\title{
Centennial evolution of the atmospheric methane budget: what do the carbon isotopes tell us?
}

\author{
K. R. Lassey ${ }^{1}$, D. M. Etheridge ${ }^{2}$, D. C. Lowe ${ }^{1}$, A. M. Smith ${ }^{3}$, and D. F. Ferretti ${ }^{1,4}$ \\ ${ }^{1}$ National Institute of Water and Atmospheric Research, P.O. Box 14-901, Wellington, New Zealand \\ ${ }^{2}$ CSIRO Marine and Atmospheric Research, PMB 1, Aspendale Vic. 3195, Australia \\ ${ }^{3}$ Australian Nuclear Science and Technology Organisation, PMB 1, Menai NSW 2234, Australia \\ ${ }^{4}$ Institute of Arctic and Alpine Research, University of Colorado, Boulder, Campus Box 450, CO 80309, USA
}

Received: 6 April 2006 - Published in Atmos. Chem. Phys. Discuss.: 21 June 2006

Revised: 12 December 2006 - Accepted: 3 April 2007 - Published: 2 May 2007

\begin{abstract}
Little is known about how the methane source inventory and sinks have evolved over recent centuries. New and detailed records of methane mixing ratio and isotopic composition $\left({ }^{12} \mathrm{CH}_{4},{ }^{13} \mathrm{CH}_{4}\right.$ and $\left.{ }^{14} \mathrm{CH}_{4}\right)$ from analyses of air trapped in polar ice and firn can enhance this knowledge. We use existing bottom-up constructions of the source history, including "EDGAR"-based constructions, as inputs to a model of the evolving global budget for methane and for its carbon isotope composition through the 20th century. By matching such budgets to atmospheric data, we examine the constraints imposed by isotope information on those budget evolutions. Reconciling both ${ }^{12} \mathrm{CH}_{4}$ and ${ }^{13} \mathrm{CH}_{4}$ budgets with EDGAR-based source histories requires a combination of: a greater proportion of emissions from biomass burning and/or of fossil methane than EDGAR constructions suggest; a greater contribution from natural such emissions than is commonly supposed; and/or a significant role for active chlorine or other highly-fractionating tropospheric sink as has been independently proposed. Examining a companion budget evolution for ${ }^{14} \mathrm{CH}_{4}$ exposes uncertainties in inferring the fossil-methane source from atmospheric ${ }^{14} \mathrm{CH}_{4}$ data. Specifically, methane evolution during the nuclear era is sensitive to the cycling dynamics of "bomb ${ }^{14} \mathrm{C}$ " (originating from atmospheric weapons tests) through the biosphere. In addition, since ca. 1970, direct production and release of ${ }^{14} \mathrm{CH}_{4}$ from nuclear-power facilities is influential but poorly quantified. Atmospheric ${ }^{14} \mathrm{CH}_{4}$ determinations in the nuclear era have the potential to better characterize both biospheric carbon cycling, from photosynthesis to methane synthesis, and the nuclear-power source.
\end{abstract}

Correspondence to: $\mathrm{K}$. R. Lassey

(k.lassey@niwa.co.nz)

\section{Introduction}

Despite considerable activity in atmospheric methane research over the past 15-20 years, little is known about how its sources and its sinks have evolved during the agro-industrial era (the past 3 centuries) of profound human influence. This era has seen a 2.5 -fold growth in the atmospheric methane burden that has not been fully interpreted in terms of the evolution of methane sources and sinks. The principal cause of this growth is the expansion of agricultural and industrial activities, including livestock farming, rice cultivation, mining of fossil fuels, reticulation of natural gas, and the largescale burning of forest and grassland biomass. The detailed histories of these anthropogenic sources are ill-determined despite efforts to reconstruct them based on historical activity data (e.g. van Aardenne et al., 2001). Other approaches apply inverse tracer modelling using detailed 3-D models over limited time ranges (Fung et al., 1991; Hein et al., 1997; Houweling et al., 1999; Cunnold et al., 2002; Mikaloff Fletcher et al., 2004; Wang et al., 2004) or use global box models over longer time scales (Etheridge et al., 1998; Dlugokencky et al., 1998; Lassey et al., 2000).

The methane source mix and its evolution can be constrained by carbon isotope data (Fung et al., 1991; Hein et al., 1997; Mikaloff Fletcher et al., 2004). Hydrogen isotope data $(\delta \mathrm{D})$ may also prove valuable (e.g. Conny and Currie, 1996; Bergamaschi et al., 2000). The carbon isotope constraint results from the distinctive isotopic "signatures" $\delta^{13} \mathrm{C}$ and/or $\Delta^{14} \mathrm{C}$ (defined in Sect. 2) of different source categories. Specifically, biogenic methane is relatively depleted in the stable isotope ${ }^{13} \mathrm{C}\left(\delta^{13} \mathrm{C} \approx-60 \%\right)$, pyrogenic methane (a by-product of biomass combustion) is relatively enriched $\left(\delta^{13} \mathrm{C}>-25 \%\right)$, and fossil methane of thermogenic origin is intermediate between these $\left(\delta^{13} \mathrm{C} \approx-40 \%\right.$ ). Furthermore, fossil sources are devoid of the radioisotope ${ }^{14} \mathrm{C}$, while biogenic and pyrogenic methane sources contain ${ }^{14} \mathrm{C}$

Published by Copernicus GmbH on behalf of the European Geosciences Union. 
levels characteristic of the atmospheric $\mathrm{CO}_{2}$ from which the carbon was photosynthetically derived, adjusted for post-photosynthesis decay. The ${ }^{14} \mathrm{C}$-free property of fossil methane has led investigators to infer the "fossil fraction" of the prevailing methane source from atmospheric ${ }^{14} \mathrm{CH}_{4}$ measurements (Lowe et al., 1988; Wahlen et al., 1989; Manning et al., 1990; Quay et al., 1991, 1999).

Studies of the evolution of atmospheric methane based on measurements of ice-entrapped air started in the early 1970s (Robbins et al., 1973). While corresponding $\delta^{13} \mathrm{C}$ determinations were reported from the late 1980s (Craig et al., 1988), sample-size requirements precluded detailed time series, and measurements were uncorrected for differential diffusion and for gravitational settling within the entrapped air bubbles (e.g. see Trudinger et al., 2002). Consequently, the sourceinventory evolution over long time scales has been poorly constrained. Longer and better resolved time series for $\delta^{13} \mathrm{C}$ are now becoming available due to small-sample developments that combine gas chromatography and stable isotope ratio mass spectrometry (GC-IRMS) (Miller et al., 2002) in conjunction with new techniques for extracting and analysing samples of old air trapped in polar firn and ice (Ferretti et al., 2005; Sowers et al., 2005). In particular, such samples from Law Dome, Antarctica, offer highly time-resolved measurements (Trudinger et al., 2002; Ferretti et al., 2005). Parallel developments in accelerator mass spectrometry (AMS) are enabling coarse-resolution air samples to be analyzed for ${ }^{14} \mathrm{CH}_{4}$ (Etheridge et al., 2001).

The methane budget evolution is also affected by changes to atmospheric sinks. The principal sink $(\sim 85 \%)$ is in situ oxidation by the $\mathrm{OH}$ radical, generated photolytically at a rate that depends in part upon the local presence of pollutants such as hydrocarbons and other volatile organic compounds, $\mathrm{CO}$ and $\mathrm{NO}_{\mathrm{x}}$. Minor sinks include consumption by methanotrophic biota in aerated soils, transport to and destruction in the stratosphere (Prather et al., 2001), and removal by other tropospheric oxidants such as active chlorine (Allan et al., 2001a). Quantitative assessment of the global $\mathrm{OH}$ trend is difficult over any time scale. However, various modelling studies agree qualitatively that global $\mathrm{OH}$ levels have declined over the industrial era (Lelieveld et al., 1998; Wang and Jacob, 1998; Houweling et al., 2000) though quantitative estimates vary over the range 7.5 to $27 \%$. Nonetheless, during recent decades that decline may have been arrested (Lelieveld et al., 2002) or, within decadal intervals, even reversed (Karlsdóttir and Isaksen, 2000; Dentener et al., 2003; Wang et al., 2004). Prinn et al. (2005) determine global-mean trends in $\mathrm{OH}$ over 25 years from a network of $\mathrm{CH}_{3} \mathrm{CCl}_{3}$ (methyl chloroform) measurements; Manning et al. (2005) determine trends over a solar cycle in the extratropical Southern Hemisphere using the quite different tracer ${ }^{14} \mathrm{CO}$. Both studies report a remarkably stable $\mathrm{OH}$, punctuated by fluctuations lasting up to a few years that reflect widescale perturbations (e.g. eruption of Mt Pinatubo in 1991).
In this paper, we present a detailed model analysis of the methane budget evolution over the 20th century during which the atmospheric burden doubled. In investigating the merit of carbon-isotope information obtained from both contemporary records and from air trapped in polar ice and firn, we: (a) explore the constraints imposed by high-resolution ${ }^{13} \mathrm{CH}_{4}$ measurements, and (b) assess the information conveyed by ${ }^{14} \mathrm{CH}_{4}$ ("radiomethane") measurements.

\section{Modelling strategy}

Global methane mass balance requires that:

$\frac{\partial C(t)}{\partial t}=S(t)-\lambda(t) C(t)$

where $S(t), \lambda(t)$ and $C(t)$ are the global source $\left(\mathrm{Tg}_{\mathrm{yr}}{ }^{-1}\right)$, sink $\left(\mathrm{yr}^{-1}\right)$ and tropospheric burden (Tg) respectively of methane at time $t$. The same equation applies separately to each "methane isotopologue", ${ }^{12} \mathrm{CH}_{4},{ }^{13} \mathrm{CH}_{4}$ and ${ }^{14} \mathrm{CH}_{4}$, but with $\lambda(t)$ augmented by radioactive decay, $\lambda_{R}$, in the case of ${ }^{14} \mathrm{CH}_{4}$. The tropospheric burden is taken to be directly proportional to mean surface mixing ratio at $2.767 \mathrm{Tg} \mathrm{ppb}^{-1}$ (Fung et al., 1991; Dlugokencky et al., 1998). Mixing ratios cited in this paper are expressed on the NOAA04 scale (Dlugokencky et al., 2005).

A corollary of Eq. (1) is that the specification of any two of $S(t), \lambda(t)$ and $C(t)$ over a time period enables the third to be inferred through "budget closure". Of these, $C(t)$ is the best-determined through the history of methane mixing ratio. MacFarling Meure et al. (2006) recently reported such a history to $2004 \mathrm{AD}$ based on analyses of air extracted from Antarctic firn and ice cores and on contemporary records from Cape Grim (Fig. 1), updating an earlier time series to 1992 AD by Etheridge et al. (1998). Thus with $C(t)$ specified, budget closure can be achieved by either: (a) prescribing the methane sink history and inferring a corresponding source history; or (b) constructing the source history and inferring a corresponding sink history. The former option is commonly pursued using a time-invariant sink (Dlugokencky et al., 1998; Lassey et al., 2000). The present work applies the latter option using published bottom-up constructions of the methane source inventory (Sect. 3), and then uses the inferred sink history to close the budget for individual isotopologues.

The methane mixing ratio appears to have been fairly steady at $\sim 700 \mathrm{ppb}$ near ca. $1700 \mathrm{AD}$, even if suppressed during the cooler temperatures of the "Little Ice Age" ca. 1300 AD-1850 AD (Etheridge et al., 1998), but it has risen almost monotonically since then (Fig. 1). We therefore commence our model integration at an imposed steady state in 1700, as per Lassey et al. (2000), through to the most recent year specified by the source history, using the mixing ratio history of Fig. 1 which is referred to as the "MM dataset".

Each source construction is likewise specified as an annual time series from 1700 (Sect. 3), even if extrapolation back 


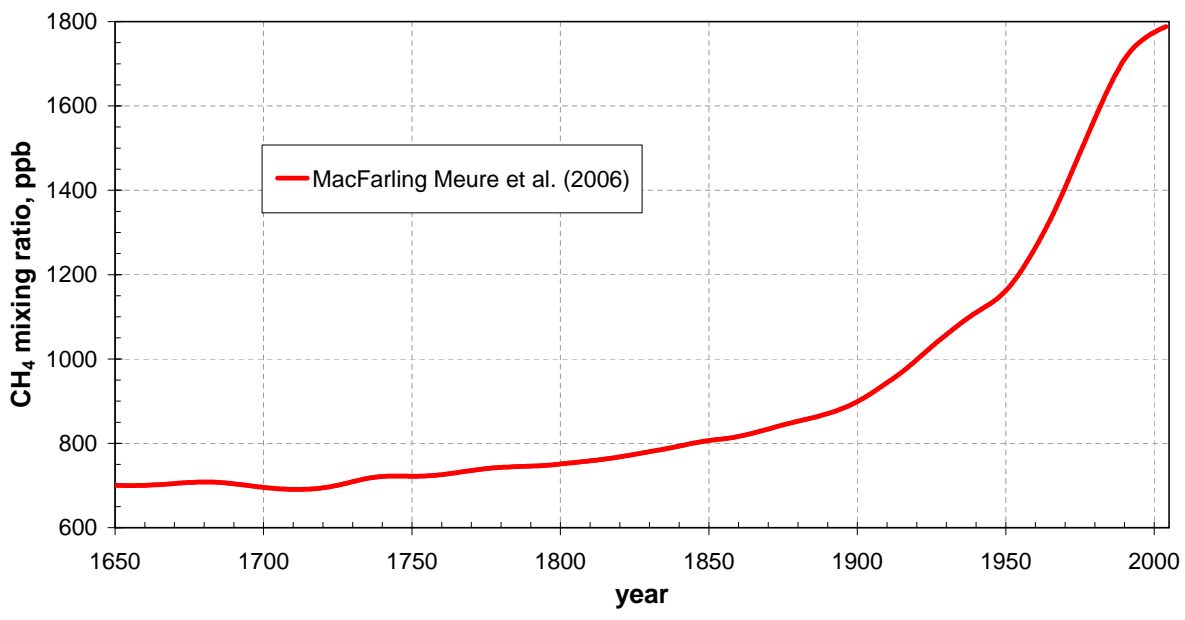

Fig. 1. The global methane mixing ratio dataset reported by MacFarling Meure et al. (2006) from 1650 AD based on detailed measurements in firn air and ice-entrapped air at Law Dome, Antarctica, and air sampled at Cape Grim, Australia. The smoothed dataset is adjusted for latitudinal gradient to a global mean by adding $37 \%$ of the inter-polar difference to the Antarctica dataset after Etheridge et al. (1998), and further adjusted to the NOAA04 scale (Dlugokencky et al., 2005). The annualized time series is referred to as the "MM dataset".

to 1700 has little supporting data. Commencing integration as early as 1700 enables the history of post-1700 disequilibrium in both mixing ratio and $\delta^{13} \mathrm{C}$ to be plausibly simulated (Lassey et al., 2000), having regard to the slow response of atmospheric $\delta^{13} \mathrm{C}$ to source perturbations (Tans, 1997).

Integration over 1-year time steps perforce ignores seasonality. This is unavoidable, not only because source constructions lack seasonal information, but also because the bubble enclosure process in the Law Dome firn and ice smoothes out compositional variations over five years or more (Trudinger et al., 2002). However, the neglect of seasonality is also reasonable when examining changes over centennial timescales. Within each time step the source and sink are held constant, enabling analytic integration of Eq. (1) so that the burden propagates from $C_{\text {beg }}$ to $C_{\text {end }}$ during a time step of duration $\Delta t$, given by:

$C_{\text {end }}=S / \lambda+\left(C_{\text {beg }}-S / \lambda\right) \exp (-\lambda \Delta t)$

We apply three alternative constructions of the source history from 1700 (Sect. 3). With the tropospheric burden $C(t)$ and source history $S(t)$ both specified at annual time steps, the mass-balancing sink history $\lambda(t)$ is deduced by solving Eq. (2) numerically in successive time steps for $\lambda$ (Sect. 3). This sink history, adjusted for time-independent isotope fractionation, is then applied separately to ${ }^{12} \mathrm{CH}_{4}$ and ${ }^{13} \mathrm{CH}_{4}$ budgets, and budget closure addressed through either forward or inverse modelling (Sect. 4). For the ${ }^{14} \mathrm{CH}_{4}$ budget, both source and sink histories are constructed and the resulting atmospheric history examined (Sect. 5).

The model treats the three methane isotopologues as independent tracers, whose abundances are transformed nonlinearly to and from the three more commonly used entities, total methane, $\delta^{13} \mathrm{C}$ and $\Delta^{14} \mathrm{C}$. Total methane is the sum of the three isotopologues, though in practice, with abundances of ${ }^{12} \mathrm{C},{ }^{13} \mathrm{C},{ }^{14} \mathrm{C}$ approximately in the ratio $0.99: 0.01: 10^{-12}$, ${ }^{14} \mathrm{CH}_{4}$ can be excluded from the sum. Aside from this exclusion, the transformations are applied without approximation. Definitions of $\delta^{13} \mathrm{C}$ and $\Delta^{14} \mathrm{C}$ follow.

Following Craig (1953):

$\delta^{13} \mathrm{C}=R / R_{\text {std }}-1$

where $R$ is the isotopic molar ratio ${ }^{13} \mathrm{C} /{ }^{12} \mathrm{C}$ in the methane sample, and $R_{\text {std }}$ is the corresponding ratio in the stable carbon isotope standard Vienna Peedee belemnite (VPDB) with accepted value 0.0112372 (Craig, 1957). While the usual "per mil" notation, \%o, is used to express both $\delta^{13} \mathrm{C}$ and $\Delta^{14} \mathrm{C}$ numerically, we omit the implicit scaling factor of 1000 from algebraic expressions such as Eq. (3). We refer to a methane sample as being isotopically "lighter" or "heavier" than another when its $\delta^{13} \mathrm{C}$ value is lower or higher (i.e. when it is less or more enriched in ${ }^{13} \mathrm{CH}_{4}$ ).

The definition of $\Delta^{14} \mathrm{C}$ is more esoteric:

$$
\Delta^{14} \mathrm{C}=A_{S N} / A_{\mathrm{abs}}-1
$$

The notation is that of Stuiver and Polach (1977, Table 1) except that we use the more usual $\Delta{ }^{14} \mathrm{C}$ in place of $\Delta$, and $\lambda_{R}$ in place of $\lambda$ for the ${ }^{14} \mathrm{C}$ radioactive decay rate $(8267 \mathrm{yr})^{-1}$. In Eq. (4a), $A_{\text {abs }}$ is the "absolute international standard activity" defined for $1950 \mathrm{AD}$ in the standard known as "0.95 NBS oxalic acid", and $A_{S N}$ is the "normalized" sample activity (assumed to be corrected for "shelf" decay between sample collection and ${ }^{14} \mathrm{C}$ analysis) expressed in terms of the measured activity $A_{S}$ through

$$
A_{S N}=A_{S}\left(\frac{0.975}{1+\delta^{13} \mathrm{C}}\right)^{2}
$$


Table 1. An indicative global inventory postulated for $1700 \mathrm{AD}$, and $\delta^{13} \mathrm{C}$ assignments ${ }^{\mathrm{a}}$.

\begin{tabular}{lcc}
\hline Source component & $\begin{array}{c}\text { Strength } \\
\mathrm{Tg} \mathrm{yr}^{-1}\end{array}$ & $\begin{array}{c}\delta^{13} \mathrm{C} \\
\% \text { No }\end{array}$ \\
\hline Wetlands & $163 \pm 78$ & -60 \\
Termites & $20 \pm 10$ & -57 \\
Wildfires & $5 \pm 0$ & -25 \\
Oceans & $15 \pm 10$ & -40 \\
Wild animals & $15 \pm 0$ & -62 \\
Geologic & $4 \pm 0$ & -40 \\
Natural subtotal & 222 & -57.4 \\
& Anthropogenic sources & \\
Coal mining & 0 & -35 \\
Other fossil & 0 & -40 \\
Farmed livestock & $5 \pm 3$ & -62 \\
Animal wastes & 0 & -55 \\
Rice cultivation & $10 \pm 5$ & -64 \\
Forest burning, woodfuel & $5 \pm 3$ & -25 \\
Savanna burning & $5 \pm 3$ & -12 \\
Waste treatment, landfills & $5 \pm 5$ & -55 \\
Anthropogenic subtotal & 30 & -47.0 \\
Total source & $\mathbf{2 5 2} \pm \mathbf{3 4}$ & $\mathbf{- 5 6 . 1} \pm \mathbf{3 . 6}$ \\
\hline
\end{tabular}

${ }^{\text {a }}$ Source strengths and $\delta^{13} \mathrm{C}$ assignments are taken from Houweling et al. (2000), except that anthropogenic biomass burning is split into forest and savanna biomass with $\delta^{13} \mathrm{C}$ assignments typical of $\mathrm{C}_{3}$ and $\mathrm{C}_{4}$ vegetation (Chanton et al., 2000). The $95 \%$ confidence intervals (CIs) for individual sources are guided by lower and upper limits assessed by Houweling et al. (2000), most of which are symmetrical about the best estimate. The CI in the total source is constrained by top-down sink uncertainty (Houweling et al., 2000). The CI in $\delta^{13} \mathrm{C}$ for the total source is calculated assuming a CI of $\pm 5 \%$ o in each $\delta^{13} \mathrm{C}$ value and is without top-down constraint.

$\mathrm{b}$ The anthropogenic inventory is notional only, and the inventory adopted for $1700 \mathrm{AD}$ is that for the earliest year specified by a particular source construction (1860 or 1890), scaled down to $30 \mathrm{Tg} \mathrm{yr}^{-1}$.

Activities $A_{\mathrm{abs}}, A_{S N}, A_{S}$ are expressed in $\mathrm{Bq}$ per gram of carbon $\left(\mathrm{Bq} \mathrm{gC}^{-1}\right)$, with the accepted value for $A_{\mathrm{abs}}$ of $0.2260 \pm 0.0012 \mathrm{~Bq} \mathrm{gC}^{-1}$ (Stuiver, 1980). The unit $\mathrm{Bq}$ (Becquerel, or disintegrations per second) equates to $433.2 \times 10^{-15}$ mole $\left({ }^{14} \mathrm{C}\right)$.

The normalization in Eq. (4b) adjusts $A_{S}$ to what it would have been had the sample had a $\delta^{13} \mathrm{C}$ value of $-25 \%$, the value for standard pre-industrial wood. This adjustment is based upon "mass-dependent isotope fractionation" in which isotope-specific chemical reaction rates, $k_{n}$, are inter-related through (e.g. Mook and van der Plicht, 1999)

$k_{14} / k_{12}=\left(k_{13} / k_{12}\right)^{2}$

With normalization (Eq. 4b), the product carbon of a reaction bears the same $\Delta^{14} \mathrm{C}$ value as the reactant carbon.
The isotope-specific sink strengths $\lambda_{n}(t)$ would also satisfy Eq. (5), with the result that the sink evolution of ${ }^{14} \mathrm{CH}_{4}$ is fully specified in terms of those of ${ }^{12} \mathrm{CH}_{4}$ and ${ }^{13} \mathrm{CH}_{4}$ :

$\lambda_{14}(t)=\alpha \lambda_{13}(t)=\alpha^{2} \lambda_{12}(t)$

with $\alpha$ the "isotope fractionation factor".

Some researchers report "percent modern carbon", pMC, in place of $\Delta^{14} \mathrm{C}$ (e.g. Wahlen et al., 1989; Manning et al., 1990; Quay et al., 1999; Nakagawa et al., 2002), a usage borrowed from radiocarbon dating and without literal meaning in geochemical application when values exceed $100 \%$ modern carbon as they do in the nuclear era. The two are related through $\mathrm{pMC}=1+\Delta^{14} \mathrm{C}$.

\section{Source construction and mass-balancing sink}

A history of methane sources from 1700 can be constructed by combining published inventories of natural sources (e.g. Lelieveld et al., 1998; Houweling et al., 2000) with "bottom-up" compilations of anthropogenic sources based on activity and production indicators or their proxies (e.g. Stern and Kaufmann, 1996; van Aardenne et al., 2001). All such constructions are subject to considerable uncertainty. We adopt three alternative anthropogenic source constructions as discussed below, each augmented by a common time-invariant natural inventory, taken to be that of Houweling et al. (2000) and totalling $222 \mathrm{Tg} \mathrm{yr}^{-1}$ (Table 1). While natural emissions may have changed over recent centuries (e.g. changes to wetland emissions due to wetland management or drainage) and may vary inter-annually with climate (Warwick et al., 2002; Dentener et al., 2003; Bousquet et al., 2006; Fiore et al., 2006), such changes are likely to be smaller than emission uncertainty, and are much smaller than emission growth from human activities.

A very recent discovery that vegetation is a source of methane (Keppler et al., 2006) has implications for preindustrial and contemporary budgets that are neither understood nor tightly quantified (Kirschbaum et al., 2006; Parsons et al., 2006; Houweling et al., 2006; Ferretti et al., 2007). Consequently, this source has yet to be integrated into source inventories, though we discuss potential implications of its inclusion.

The few available constructions of the anthropogenic source history are confined to the past $\sim 100-150$ years. We adopt the proxy-based construction of Stern and Kaufmann (1996, see also http://cdiac.ornl.gov/ trends/meth/ch4.htm) for 1860-1994 (hereafter abbreviated "S\&K"), and two versions of the EDGAR-HYDE inventory (http://mnp.nl/edgar/). The EDGAR-HYDE datasets (hereafter "E-H") are available as two alternate time series: (1) version 1.3 ("E-H v1.3") based on EDGAR 2.0 and described by van Aardenne et al. (2001) provides emission inventories every ten years, 1890-1990; and (2) version 1.4 ("E-H v1.4"), adjusted to match EDGAR 3.2 (Olivier and 
Berdowski, 2001; Olivier, 2002), provides inventories every ten years, 1890-1970, then yearly to 1995 .

We refer to each of the three anthropogenic source histories, augmented by a fixed natural source inventory, annualized, and extrapolated back to 1700 , as a "global source inventory history" (GSIH) and shown in Fig. 2a from 1880.

In developing a plausible extrapolation of each GSIH back to 1700 , we note the evidence by several researchers that an anthropogenic influence on methane emissions commenced well before the industrial era (e.g. Kammen and Marino, 1993; Subak, 1994; Houweling et al., 2000; Ruddiman and Thomson, 2001; Ferretti et al., 2005). Houweling et al. (2000) assessed the pre-industrial anthropogenic source at $30 \mathrm{Tg} \mathrm{yr}^{-1}$, a value which we here associate with ca. 1700 . A linear interpolation between $30 \mathrm{Tg} \mathrm{yr}^{-1}$ in 1700 and the commencement of each source construction (1860 or 1890) preserves the proportional composition of the latter so that each anthropogenic inventory in 1700 differs slightly from that of Table 1. While linear interpolation is clearly an idealization in the absence of guiding data, it should assure that the disequilibrium in $\delta^{13} \mathrm{C}$ propagates more realistically than spinning up from an initial state postulated for 1860 or 1890 .

In summary, we employ three constructed GSIHs based on S\&K, E-H v1.3 and E-H v1.4 (Fig. 2a). The source strength increases from $252 \mathrm{Tg} \mathrm{yr}^{-1}$ in 1700 to either $593 \mathrm{Tg} \mathrm{yr}^{-1}$ in 1994 (S\&K), $542 \mathrm{Tg} \mathrm{yr}^{-1}$ in 1990 (E-H v1.3) or $524 \mathrm{Tg} \mathrm{yr}^{-1}$ in 1995 (E-H v1.4). It is clear (Fig. 2a) that both E-H GSIHs are weaker than S\&K, especially since ca. 1960, and probably weaker than the global source strength that closes the contemporary "top-down" budget estimated at 600 (495700) $\mathrm{Tg} \mathrm{yr}^{-1}$ (Schimel et al., 1996; Prather et al., 2001).

From the source and atmospheric histories of total methane the sink history required by mass balance, $\lambda(t)$, can be derived by solving Eq. (2) numerically at each time step. The result is shown in Fig. $2 b$ in the form of turnover time $\tau(t)=\lambda(t)^{-1}$. The sinks matching the three GSIHs all display a weakening trend through the 20th century, qualitatively supporting the assessment of Lelieveld et al. (1998) and others of a slowed methane removal rate through the industrial era. In the 1980s all three sinks strengthen, qualitatively in line with chemistry-model calculations by Karlsdóttir and Isaksen (2000) and by Dentener et al. (2003). Those calculations appear to report lifetime against $\mathrm{OH}$ removal and while this differs in definition from turnover time $\tau$, that difference is manifested mainly as an offset leaving the trends directly comparable.

\section{Mass balance of ${ }^{13} \mathrm{CH}_{4}$ and the atmospheric history of $\delta^{13} \mathbf{C}$}

Two approaches are possible for modelling the evolution of ${ }^{13} \mathrm{CH}_{4}$. Both employ the mass-balancing sink history (Fig. 2b) from which separate sinks for ${ }^{12} \mathrm{CH}_{4}$ and ${ }^{13} \mathrm{CH}_{4}$ follow once an isotopic fractionation is specified (Sect. 4.1).
In the first approach (Sect. 4.2), source histories for ${ }^{12} \mathrm{CH}_{4}$ and ${ }^{13} \mathrm{CH}_{4}$ are constructed and the respective atmospheric histories are deduced by forward modelling. The second approach (Sect. 4.3) exploits the detailed $\delta^{13} \mathrm{C}$ time series now obtainable from air archived in polar ice and firn, enabling the $\delta^{13} \mathrm{C}$ history in the global source to be inferred through inverse modelling of ${ }^{13} \mathrm{CH}_{4}$.

\subsection{The evolving ${ }^{13} \mathrm{CH}_{4}$ sink}

With the usual assumption that $\lambda_{12}$ and $\lambda_{13}$ are related through a fixed isotope fractionation factor $\alpha=\lambda_{13}(t) / \lambda_{12}(t)$, it is straightforward to deduce $\lambda_{12}(t)$ and $\lambda_{13}(t)$ separately from the inferred sink history $\lambda(t)$ in each time step by imposing mass balance for total methane and for each methane isotopologue. (Note our convention that $\alpha$ is defined with the minor isotope in the numerator, consistently with definition (3) for $\delta^{13} \mathrm{C}$ ). Formally

$\lambda_{13}=\alpha \lambda_{12}=\frac{1+W}{1+\alpha W} \alpha \lambda$

in which $W$ is the tropospheric mass ratio, ${ }^{13} \mathrm{CH}_{4}:{ }^{12} \mathrm{CH}_{4}$, in that time step given by

$W=\frac{17}{16} R_{\text {std }}(1+\delta)$

with $\delta$ denoting the tropospheric $\delta^{13} \mathrm{C}$ value.

For multiple first-order methane sinks, $\alpha$ is the sinkweighted fractionation factor. Reported values for the dominant $\mathrm{OH}$ sink are $\alpha_{\mathrm{OH}}=0.9946 \pm 0.0009$ (Cantrell et al., 1990) and $\alpha_{\mathrm{OH}}=0.9961 \pm 0.0004$ (Saueressig et al., 2001); both of these are laboratory-based determinations and the cited uncertainties are $95 \%$ confidence intervals. The departure of $\alpha$ from unity is referred to as the kinetic isotope effect or KIE. It is useful to use $\varepsilon=\alpha-1$, expressed in $\%$, to quantify the KIE, so that $\varepsilon_{\mathrm{OH}}$ values that correspond to the above measured values for $\alpha_{\mathrm{OH}}$ are $-5.4 \%$ and $-3.9 \%$, respectively. Separate KIEs apply to each removal process: for the soil sink $\varepsilon_{\text {soil }}$ is near $-20 \%$ (Tyler et al., 1994a; Snover and Quay, 2000), while for a minor active-chlorine sink $\varepsilon_{\text {chlorine }}$ is near $-60 \%$ o (Saueressig et al., 1995; Crowley et al., 1999; Tyler et al., 2000).

The large range of individual KIE values and uncertain relative sink strengths confer appreciable uncertainty on the "bottom-up" KIE value, $\varepsilon_{\text {total }}$, for which Table 2 derives a plausible value of $-7.7 \pm 1.4 \%$ ( $95 \%$ confidence interval).

The entry in Table 2 for the stratospheric sink may require explanation. Multiple chemical loss processes via $\mathrm{OH}$, $\mathrm{O}\left({ }^{1} \mathrm{D}\right), \mathrm{Cl}$ are estimated to remove $40 \pm 8 \mathrm{Tg} \mathrm{yr}^{-1}$ from the contemporary stratosphere (Schimel et al., 1996; Lelieveld et al., 1998), and in doing so discriminate against ${ }^{13} \mathrm{CH}_{4}$ (e.g. Bergamaschi et al., 1996). Methane that survives oxidation is returned to the troposphere, but the re-entry flux is poorly known or unknown. Measurements of methane mixing ratio and $\delta^{13} \mathrm{C}\left(\mathrm{CH}_{4}\right)$ in the mid-latitude lower stratosphere which 

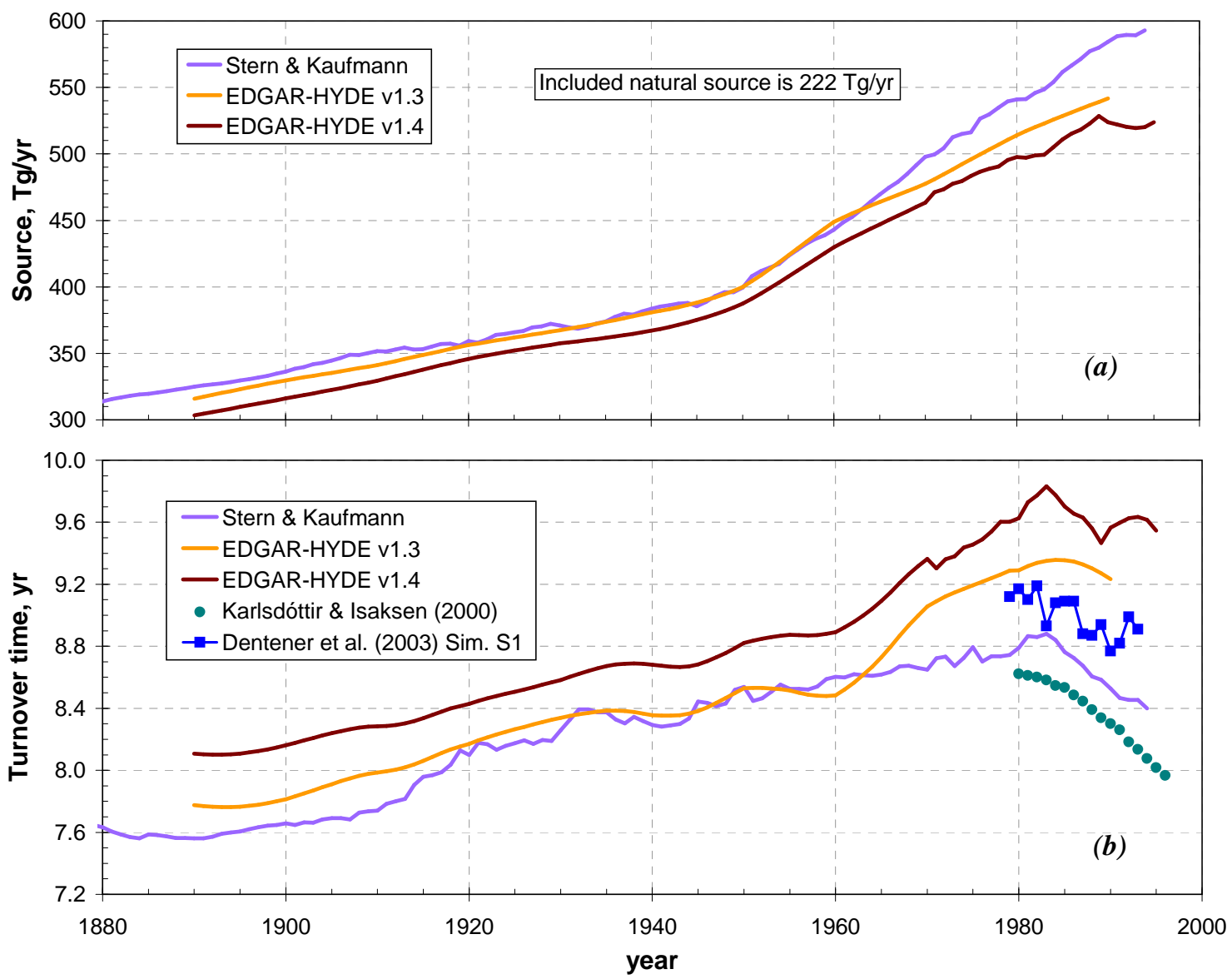

Fig. 2. (a) Three "bottom-up" constructions of the anthropogenic source history, each augmented by a natural source of $222 \mathrm{Tg} \mathrm{yr}^{-1}$. Each construction, with its underlying inventory, is referred to as a "Global Source Inventory History" (GSIH). (b) The histories of methane turnover time, $\tau(t)=\lambda(t)^{-1}$, corresponding to the three GSIHs and consistent with the mixing ratio history of Fig. 1. Also shown are model calculations by Karsldóttir and Isaksen (2000) and by Dentener et al. (2003, Simulation S1) of turnover times due to the OH sink alone for which trends, but not absolute values, can be compared with $\tau(t)$.

is the site of much of that re-entry (Waugh and Hall, 2002) are consistent with removal by Rayleigh distillation with an isotope fractionation of about $-12 \%$ o (Brenninkmeijer et al., 1995; Bergamaschi et al., 1996; Sugawara et al., 1997). The ${ }^{13} \mathrm{CH}_{4}$ enrichment actually realised in a parcel of air re-entering the troposphere depends upon the stratospheric "age" of that parcel at re-entry compared to the "chemical lifetime" of methane due to exposure to oxidants along its stratospheric trajectory. The mean air age in the mid-latitude lower stratosphere is $\sim 4$ years (Waugh and Hall, 2002), probably much shorter than the ill-determined chemical lifetime that can be scoped at $(\sim 410 \mathrm{Tg}) /\left(30 \mathrm{Tg} \mathrm{yr}^{-1}\right) \approx 14 \mathrm{yr}$, suggesting that the re-entry flux is too "young" for appreciable ${ }^{13} \mathrm{CH}_{4}$ enrichment. The latter estimate is from model simulations by Struthers et al. (2007) showing a stratospheric methane burden of $\sim 410 \mathrm{Tg}$ in steady state with an imposed sink $\left(\mathrm{OH}+\mathrm{O}\left({ }^{1} \mathrm{D}\right)+\mathrm{Cl}\right)$ of $30 \mathrm{Tg} \mathrm{yr}^{-1}$ that account for the data reported by Sugarawa et al. (1997) (H. Struthers, personal communication, 2007). That same model analysis (Struthers et al., 2007) simulates a $\delta^{13} \mathrm{C}$-contrast between troposphere and stratosphere, calculated as if each were well mixed, of $1.9 \%$. Since steady state does not prevail and the stratosphere is highly stratified with much higher enrichment in the upper stratosphere (Bergamaschi et al., 1996; McCarthy et al., 2001), one would expect a somewhat smaller contrast in the vicinity of the tropopause. This is consistent with measurements reported for the lower stratosphere south of latitude $43^{\circ} \mathrm{S}$ (Brenninkmeijer et al., 1995) that reveal enrichments of $<1 \%$ relative to contiguous tropospheric $\delta^{13} \mathrm{C}$ values, and also with modelled steady-state $\delta^{13} \mathrm{C}$ contrasts near the tropopause of $1 \%$ (McCarthy et al., 2001) that provide consistency with measurements by Sugawara et al. (1997). In our 1-box model of the troposphere, unidirectional stratospheric loss is a proxy for the net tropospherestratosphere methane flux with associated effective fractionation, $\varepsilon_{\text {stratosphere }}$, of magnitude $\left(F_{S T} / F_{\text {net }}\right) \Delta \delta^{13} \mathrm{C}$ in which $F_{S T}$ and $F_{\text {net }}$ are the gross stratosphere-troposphere and net methane fluxes respectively, and $\Delta \delta^{13} \mathrm{C}$ is the contrast in 
$\delta^{13} \mathrm{C}\left(\mathrm{CH}_{4}\right)$ between the gross fluxes. The null bound for $\varepsilon_{\text {stratosphere }}$ in Table 2 corresponds to a neglible re-entry flux (i.e. transport-mediated loss). The mid-range estimate for $\varepsilon_{\text {stratosphere }}$ conservatively accommodates the above assessments for $\Delta \delta^{13} \mathrm{C} \approx 1 \%$ o combined with plausible estimates of the gross troposphere-stratosphere methane flux, $F_{S T}+F_{\text {net }}$. Based on an estimate by Wang et al. (2002) of the upward advective mass flow across $100 \mathrm{hPa}$ in the tropics of $1.4 \times 10^{17} \mathrm{~kg}$ air $\mathrm{yr}^{-1}$ and a contemporary methane content of $1.7 \mathrm{ppm}$ in this flow, the gross upward methane flux would be $130 \mathrm{Tg} \mathrm{yr}^{-1}$, implying $F_{S T} \approx 90 \mathrm{Tg} \mathrm{yr}^{-1}$. The Wang et al. air-flow estimate is half an earlier estimate (Rosenlof and Holton, 1993), so this upward methane flux carries appreciable uncertainty. (An upward methane flux consistent with the Rosenlof and Holton estimate would be almost half the methane source at the surface and so would imply a fast mean stratospheric turnover of methane). It should be noted that a choice of $\varepsilon_{\text {stratosphere value within the range }-3 \pm 3 \% \text { is }}$ not material, imposing changes on the sink-weighted $\varepsilon_{\text {total }}$ of $0.2 \pm 0.2 \%$ and therefore enriching tropospheric $\delta^{13} \mathrm{C}$ by the same amount at steady state. By comparison, McCarthy et al. (2001) assess that stratospheric chemistry and transport enriches tropospheric $\delta^{13} \mathrm{C}\left(\mathrm{CH}_{4}\right)$ by $0.5-0.6 \%$ at steady state of which $0.5 \%$ is due to anthropogenic stratospheric chlorine alone. The latter role has changed significantly in a CFC-perturbed stratosphere, and Wang et al. (2002) reassess tropospheric enrichment for 1992 due to stratospheric chlorine without assuming steady state at $0.23 \%$ o $(0.18-0.54 \%$ o). While the above assessment treats stratosphere-troposphere exchange only superficially, it does suggest that the choice of $\varepsilon_{\text {stratosphere }}$ in Table 2 is reasonable.

Although the chlorine sink in Table 2 is of minor and uncertain magnitude, it discriminates strongly between isotopologues and therefore exerts large "isotope leverage" on $\varepsilon_{\text {total }}$ : in its absence, the bottom-up estimate for $\varepsilon_{\text {total }}$ in Table 2 would be $-5.4 \pm 0.8 \%$. The chlorine sink has been invoked to explain the large $\delta^{13} \mathrm{C}$ seasonal amplitude observed in the SW Pacific region (Allan et al., 2001a, b; Platt et al., 2004), and a varying chlorine sink to explain inter-annual variability in those amplitudes (Allan et al., 2005, 2007). However, while this approach estimates the seasonal amplitude in the putative chlorine sink that can account for the "seasonal KIE" (Allan et al., 2001b), it only weakly constrains the annualmean chlorine sink (Allan et al., 2007; W. Allan, personal communication, 2006).

Our approach is to select an apparent, or "top-down", KIE value, $\varepsilon$, for each GSIH that optimizes the match between atmospheric observation and simulation. From the quality of that match and through comparison with the "bottom-up" estimate $\varepsilon_{\text {total }}=-7.7 \pm 1.4 \%$, inferences can be drawn about that GSIH and/or sink. This is analogous to applying a topdown approach to better constrain the global source than by bottom-up source aggregation.
Table 2. Typical construction of an aggregate sink for tropospheric methane ${ }^{\mathrm{a}}$.

\begin{tabular}{lcc}
\hline Sink & $\begin{array}{c}\text { Strength } \\
\operatorname{Tg~yr}^{-1}\end{array}$ & $\begin{array}{c}\varepsilon_{\text {sink }} \\
\% \text { oo }\end{array}$ \\
\hline OH & $490 \pm 85$ & $-4.65 \pm 0.75$ \\
soil & $30 \pm 15$ & $-20 \pm 2$ \\
stratosphere & $40 \pm 8$ & $-3 \pm 3$ \\
chlorine & $25 \pm 12$ & $-60 \pm 1$ \\
total & $\mathbf{5 8 5} \pm \mathbf{8 8}$ & $\mathbf{- 7 . 7} \pm \mathbf{1 . 4}$ \\
\hline
\end{tabular}

a Contemporary sink strengths and fractionations with $95 \%$ confidence intervals (CIs) for first-order sinks. All sink strengths except chlorine are from the IPCC Second Assessment Report (Schimel et al., 1996); the Third Assessment Report (Prather et al., 2001) neither substantially updates these nor supplies uncertainty estimates. The chlorine sink is from Allan et al. (2007) who cite $25 \mathrm{Tg} \mathrm{yr}^{-1}$ as a mid-point between bounds assessed at 13 and $37 \mathrm{Tg} \mathrm{yr}^{-1}$. The value for each $\varepsilon_{\text {sink }}$ is literature based (see text) with $\varepsilon_{\mathrm{OH}}$ the mean of two published values (Cantrell et al., 1990; Saueressig et al., 2001). The CI in each individual $\varepsilon_{\text {sink }}$ accounts for the spread in measured values. CIs for the total sink and for the corresponding $\varepsilon_{\text {total }}$ are bottom-up calculations that assume all individual CIs to be uncorrelated.

$\mathrm{b}$ The stratospheric sink strength is estimated from reactions of methane with $\mathrm{OH}, \mathrm{O}\left({ }^{1} \mathrm{D}\right), \mathrm{Cl}$ in the stratosphere itself, all of which discriminate against ${ }^{13} \mathrm{CH}_{4}$. Viewed as the net upward crosstropopause methane flux, the effective fractionation is estimated from the $\delta^{13} \mathrm{C}$ contrast in the two gross fluxes, themselves poorly determined. See Sect. 4.1 for the detail of this estimate.

\subsection{Forward modelled ${ }^{13} \mathrm{CH}_{4}$}

To each inventory component in each GSIH a representative $\delta^{13} \mathrm{C}$ signature is assigned (Table 1). The weighted sum provides a "bottom-up" $\delta^{13} \mathrm{C}$ history, denoted $\delta_{S}(t)$, as companion to each GSIH strength, enabling separate ${ }^{12} \mathrm{CH}_{4}$ and ${ }^{13} \mathrm{CH}_{4}$ source histories to be derived.

Uncertainties in individual global $\delta^{13} \mathrm{C}$ assignments, and thence in $\delta_{S}(t)$, are difficult to assess and potentially subjective. Few if any assignments are based on measurements with wide spatial (or temporal) coverage, so that estimates of a global-mean $\delta^{13} \mathrm{C}$ and its uncertainty tend to reflect the distribution of measurements rather than the distribution of emissions. Consequently, different compilations of uncertainties can differ markedly, even while citing similar data sources. For example, Hein et al. (1997, Table 8) quote 95\% confidence intervals ( 2 s.d.) in the range \pm 2 to $\pm 5 \%$ o with a $\delta^{13} \mathrm{C}$ value of $-59 \pm 5 \%$ o quoted for "swamps" (the dominant sub-category of wetlands), whereas Quay et al. (1999, Table 1) quote 1 s.d. in the range \pm 2 to $\pm 7 \%$, with $-60 \pm 5 \%$ o for wetlands. For the purposes of illustrating uncertainty in $\delta_{S}(t)$, our judgement is to associate with each source a $95 \%$ confidence interval of $\pm 5 \%$ as being realistic even if not rigorous. As long as uncertainties in $\delta^{13} \mathrm{C}$ assignments 
dominate over those in source strengths, the "bottom-up" uncertainty in $\delta_{S}(t)$ will always be smaller than the $\pm 5 \%$; an estimate for the pre-industrial source is $\pm 3.6 \%$ (Table 1 ). Moreover, revising an individual $\delta^{13} \mathrm{C}$ value for a persistent source such as wetlands within its $\pm 5 \%$ o uncertainty will result mainly in translating the $\delta_{S}(t)$ pattern (i.e. changing its offset) with a lesser effect on its time-dependence. Thus, that pattern in $\delta_{S}(t)$ will be more robust than its actual magnitude.

From the constructed ${ }^{12} \mathrm{CH}_{4}$ and ${ }^{13} \mathrm{CH}_{4}$ source histories and the corresponding sink histories (with $\varepsilon$ specified), the tropospheric ${ }^{12} \mathrm{CH}_{4}$ and ${ }^{13} \mathrm{CH}_{4}$ burdens are deduced by forward modelling (Eq. 2). These can be transformed to $C(t)$ and companion $\delta^{13} \mathrm{C}$ evolutions, the latter denoted $\delta_{A}(t)$. The former, re-expressed as a mixing ratio, recovers the MM dataset. To first order $\delta_{A}(t)$ is given by $\delta_{S}(t)-\varepsilon+$ disequilibrium correction (Lassey et al., 2000), so that varying $\varepsilon$ essentially translates the $\delta_{A}(t)$ pattern parallel to the $\%$ o-axis, and for each GSIH an "apparent $\varepsilon$ " can be selected to optimize the fit of $\delta_{A}(t)$ to 20th century data (Fig. 3a).

It is clear that for the E-H sources in particular, the $\delta_{A}(t)$ pattern matches the observed pattern adequately for ca. 1910-1990. For S\&K the pattern match is less acceptable, displaying in particular a rate of change of $\delta_{A}(t)$ that is systematically too small for ca. $1930-1950$ then too great for ca. 1950-1970. The poor fits before ca. 1910 may be simply due to the less realistic source constructions in the prior decades in combination with the slow responsiveness of $\delta^{13} \mathrm{C}$ to source changes (Tans, 1997; Lassey et al., 2000), and/or could be a result of a mis-assigned $\delta^{13} \mathrm{C}$ for wetlands (discussed below).

All data reported in Fig. 3a are from Southern Hemisphere (SH) sites. In particular, the post-1990 data rely heavily on the NIWA record for Baring Head (BHD), New Zealand, which is matched also by that for Scott Base, Antarctica (Lowe et al., 2004). The BHD record is based on high frequency sampling $\left(\sim 20 \mathrm{yr}^{-1}\right)$ at a recognized clean-air station, with data filtered for wind speed and direction. Cleanair records of comparable frequency are unavailable for the Northern Hemisphere (NH). The BHD record features an "anomaly" in ca. 1992 in which $\delta^{13} \mathrm{C}$ fell markedly by $\sim 0.2 \%$, followed by a slow recovery that a decade later has still not attained pre-1992 levels. This anomaly has been subjected to scrutiny (Lowe et al., 1997; Mak et al., 2000), and while it remains ill-explained, trans-equatorial transects (Mak et al., 2000) and NH observational records (Quay et al., 1999) suggest that it was largely confined to the extratropical SH, where available records cannot establish its geographical extent: for example, it is not visible in the lowfrequency Cape Grim air archives (Francey et al., 1999).

The SH observations are reported in Fig. 3a along with simulated global means. It is well established that deseasonalised SH methane is isotopically heavier than its $\mathrm{NH}$ counterpart by $\sim 0.3 \%$ o (Lowe et al., 1999; Quay et al., 1999; Miller et al., 2002). Such a N-S gradient is expected because with $\sim 75 \%$ of sources in the NH (Fung et al., 1991) and
${ }^{12} \mathrm{CH}_{4}$ being removed faster than ${ }^{13} \mathrm{CH}_{4}$, methane in the $\mathrm{SH}$ has been airborne longer, is less abundant, and thence is isotopically heavier than its $\mathrm{NH}$ counterpart. Thus, global-mean $\delta^{13} \mathrm{C}$ histories would be $\sim 0.15 \%$ o lighter than the SH datasets in Fig. 3a. With this "global adjustment" to data in Fig. 3a, taken as $0.2 \%$, the apparent $\varepsilon$ for $\mathrm{S} \& \mathrm{~K}, \mathrm{E}-\mathrm{H}$ v1.3 and E-H v1.4 become $-7.9,-6.7$ and $-7.2 \%$, respectively.

The apparent $\varepsilon$ values (Fig. 3a) generally agree well with bottom-up estimation (Table 2). However, the latter is sensitive to the magnitude of the poorly-quantified chlorine sink. The chlorine sink strength in Table 2 bisects adjudged bounds that are based on a postulated seasonal structure throughout the marine boundary layer with a seasonal amplitude calibrated by SW Pacific data (Allan et al., 2007; W. Allan, personal communication, 2006). Without the chlorine sink the bottom-up estimate for $\varepsilon_{\text {total }}$ would be $-5.4 \pm 0.8 \%$ o, while for an intermediate chlorine strength of $10 \pm 9 \mathrm{Tg} \mathrm{yr}^{-1}$ consistent with Platt et al. (2004), that estimate would be $-6.3 \pm$ $1.2 \%$, an estimate close to that adopted elsewhere (Lassey et al., 2005; Ferretti et al., 2007). Thus a weaker chlorine sink would exacerbate the discrepancy between apparent $\varepsilon$ and bottom-up $\varepsilon_{\text {total }}$ by up to $\sim 2.4 \%$ o. It is instructive therefore to examine explanations that could collectively account for that discrepancy in the presence of a weaker chlorine sink, most involving an isotopically heavier source. In order of likely decreasing importance, these include: (a) some GSIHs may have unrealistic source mixes, especially the mix of biogenic, fossil, and pyrogenic methane; (b) one or more $\delta^{13} \mathrm{C}$ assignments for major inventory components are too light; (c) the newly-discovered terrestrial-plant source (Keppler et al., 2006) is unaccounted for; $(d)$ the fractionation associated in Table 2 with the dominant $\mathrm{OH}$ sink may be erroneous. We consider these four contenders in turn.

GSIH mix. A global source with a greater proportion of pyrogenic and/or fossil methane (ie, relatively less biogenic methane) will be isotopically heavier and therefore require a smaller apparent $|\varepsilon|$ value. Pyrogenic methane in particular exerts appreciable isotopic leverage on $\delta^{13} \mathrm{C}$ in the global source, especially from $\mathrm{C}_{4}$ vegetation as fuel (Chanton et al., 2000). $C_{4}$ vegetation includes savanna and other grasses prevalent in Africa, South America and northern Australia, together with agricultural crops such as maize and sugar cane. Moreover, assessments of the quantity of biomass fuel and its $\mathrm{C}_{3}: \mathrm{C}_{4}$ mix are highly uncertain (Kasischke and Penner, 2004; Mouillot et al., 2006), and the proportion of the carbon fuel emitted as methane is highly variable (Andreae and Merlet, 2001), with the result that the global pyrogenic methane source and its mean $\delta^{13} \mathrm{C}$ signature are poorly determined. In addition, some fossil methane emissions such as from abandoned coal mines (e.g. Kirchgessner et al., 2000), or from natural gas seepages (Lacroix, 1993; Etiope and Klusman, 2002; Etiope, 2004) are poorly quantified and may be under-represented in the GSIH's used here. Furthermore, larger pyrogenic and/or fossil components will not only make the E-H sources isotopically heavier, but the stronger global 

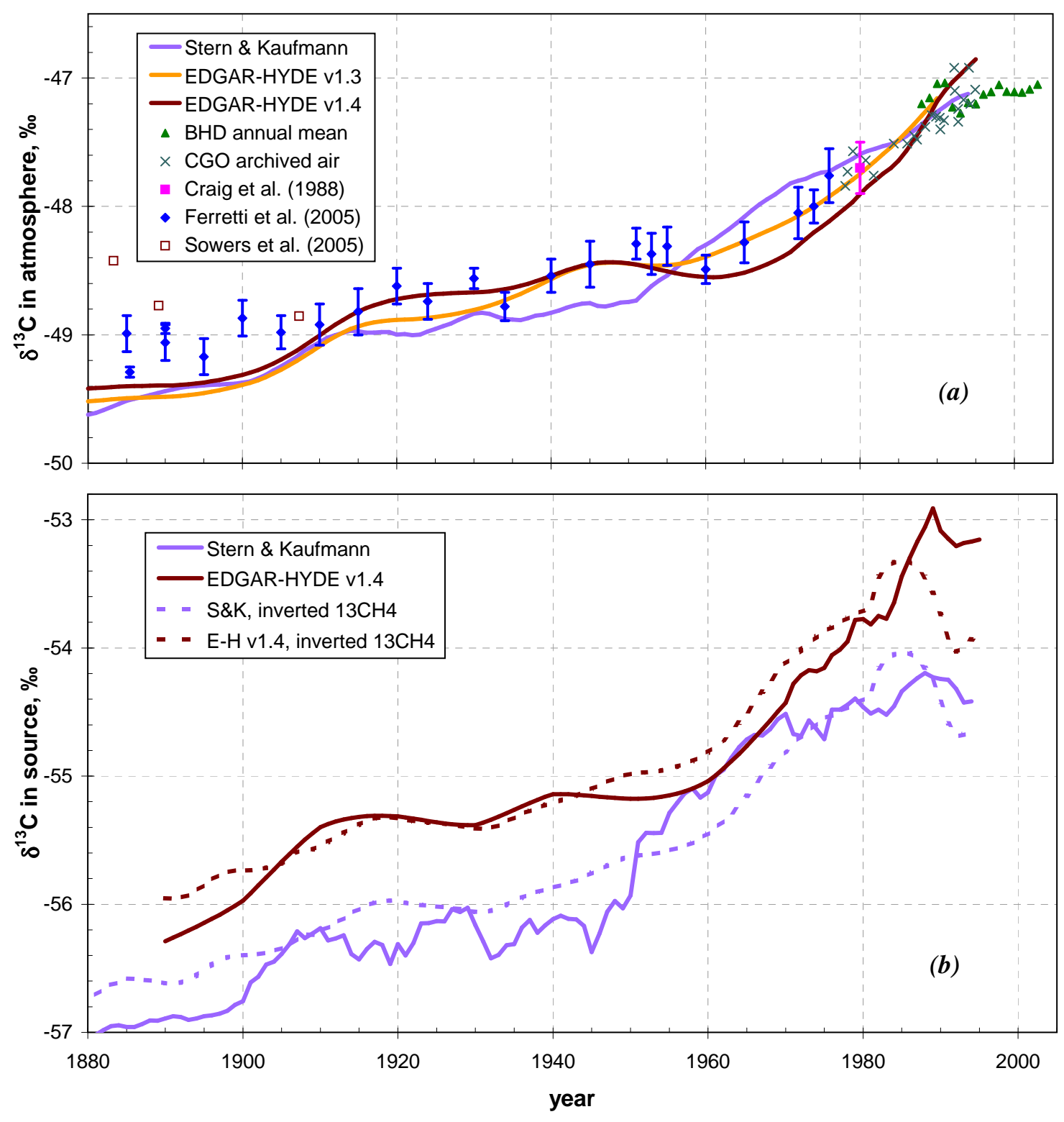

Fig. 3. (a) The modelled histories of $\delta^{13} \mathrm{C}$ in atmospheric methane, $\delta_{A}(t)$, based on the three GSIHs of Fig. 2a combined with $\delta^{13} \mathrm{C}$ assignments for individual sources (Table 1), and corresponding sink histories of Fig. 2b. Available data, all from the Southern Hemisphere (SH), are also shown: air trapped in polar firn or ice as indicated; air archived at Cape Grim Observatory (Francey et al., 1999); contemporary time series of annual means from Baring Head (updated from Lowe et al., 2004). The KIE value, $\varepsilon$, optimized separately for each source history S\&K, E-H v1.3 and E-H v1.4, is $-8.1 \%,-6.9 \%$ and $-7.4 \%$ o respectively; to these values should be added an adjustment of $\sim 0.2 \% \circ$ to "globalise" the SH datasets (see text, Sect. 4.2). (b) The source history of $\delta^{13} \mathrm{C}, \delta_{S}(t)$, used to generate panel (a) for S\&K and for E-H $\mathrm{v} 1.4$ (solid lines), compared with the corresponding $\delta_{S}^{\text {inv }}(t)$ deduced by inverse modelling with smoothed atmospheric $\delta^{13} \mathrm{C}$ (dotted lines). The corresponding history for E-H v1.3 is little different from E-H v1.4 apart from an offset in the range $0.4-0.8 \%$.

source will better match independent top-down assessments (Prather et al., 2001).

Source $\delta^{13} \mathrm{C}$ assignments. Only for a major source such as global wetlands (assigned $\delta^{13} \mathrm{C}$ value $-60 \%$ o, uncertainty $\sim 5 \%$ o can a reassignment of $\delta^{13} \mathrm{C}$ materially and systematically affect the weighted mean $\delta_{S}(t)$ and thence the apparent $\varepsilon$. Wetlands accounted for $\sim 60 \%$ of the global methane source in ca. 1900, declining to $\sim 35 \%$ in ca. 2000. Mikaloff Fletcher et al. (2004) assign a value $-58 \%$ to $\delta^{13} \mathrm{C}$ of the global wetland source which if adopted here for E-H v1.4 would raise $\delta_{S}(t)$ by $\sim 1.2 \%$ in ca. 1900 declining to $\sim 0.7 \%$ o a century later. Thus, a re-assigned (heavier) wetland $\delta^{13} \mathrm{C}$ would reduce the apparent $|\varepsilon|$, and through a greater wetland role nearer the beginning of the century could also improve 
the quality of the fit in those early years. No other source is persistently prominent enough for a reassigned $\delta^{13} \mathrm{C}$ to modify $\delta_{S}(t)$ while substantially preserving its centennial pattern.

Plant-sourced methane. Inclusion into the source inventory of the newly-discovered plant source (Keppler et al., 2006) would strengthen the global source. However, with a $\delta^{13} \mathrm{C}$ value close to that of the mean source (averaging $-50 \%$, according to Keppler et al. (2006), but dependent on the emission mix from $\mathrm{C}_{3}$ and $\mathrm{C}_{4}$ vegetation), that inclusion would have insufficient leverage to dramatically influence $\delta^{13} \mathrm{C}$ in the global source. If however that source were included at the partial expense of biogenic methane from wetlands or rice cultivation to avoid possible double-counting of methane from those ecosystems, then the global source could be heavier and the apparent $|\varepsilon|$ correspondingly smaller. For example, including $60 \mathrm{Tg} \mathrm{yr}^{-1}$ of global plant methane with signature $-50 \%$ into the contemporary inventory at the expense of $30 \mathrm{Tg} \mathrm{yr}^{-1}$ of biogenic methane $(-60 \%$ ) would result in a global source that was both $30 \mathrm{Tg} \mathrm{yr}^{-1}$ stronger and $\sim 0.7 \%$ o heavier.

Fractionation in the $\mathrm{OH}$ sink. Direct determinations of $\varepsilon_{\mathrm{OH}}$ are inevitably laboratory based (Cantrell et al., 1990; Saueressig et al., 2001) and therefore open to question about transferability to the real-world atmosphere. Specifically, in the laboratory setting $\mathrm{OH}$ is artificially generated to artificially high $\mathrm{OH}$ density $\left(\sim 10^{10} \mathrm{~cm}^{-3}\right)$ over a limited range of reactant temperatures with a possibly significant co-generation of other oxidants (e.g. $\left.\mathrm{O}\left({ }^{1} \mathrm{D}\right)\right)$. Furthermore, those two most recent determinations differ significantly $(-5.4 \pm 0.9 \%$ and $-3.9 \pm 0.4 \%$, respectively, with $95 \%$ confidence intervals), a difference which Saueressig et al. (2001) argue is not a consequence of interference by $\mathrm{O}\left({ }^{1} \mathrm{D}\right)$. Thus the possibility that neither correctly reflect $\varepsilon_{\mathrm{OH}}$ in the real atmosphere cannot be dismissed.

\subsection{Inverse modelled ${ }^{13} \mathrm{CH}_{4}$}

A growing body of ${ }^{13} \mathrm{CH}_{4}$ data from air extracted from polar ice and firn allows an alternative approach to the evolving mass balance. Sowers et al. (2005) and Ferretti et al. (2005) have reported data from Antarctic sites for air ages spanning the past two centuries and the past two millennia, respectively. The post-1880 datasets are reported in Fig. 3a. From these datasets can be derived a smoothed annualized time series for atmospheric $\delta^{13} \mathrm{C}$ that enable the ${ }^{12} \mathrm{CH}_{4}$ and ${ }^{13} \mathrm{CH}_{4}$ budgets to be closed by inverse modelling, yielding the corresponding sources, $S_{12}$ and $S_{13}$.

An atmospheric $\delta^{13} \mathrm{C}$ time series is generated by applying a smoothed fit to the combination of the Ferretti et al. (2005) dataset (to 1976) and contemporary high-frequency Baring Head dataset (annual means, 1988-2003) updated from Lowe et al. (2004), with guidance from analyses of air archived from Cape Grim during 1978-1994 (Francey et al., 1999). The smoothing algorithm distinguishes variations in $\delta^{13} \mathrm{C}$ that are not statistically proven from those that are well supported. It specifically weakens the "anomaly" of 19881994 in recognition of its possibly limited geographical extent. We refer to the annualized time series, 1700-2003, as the Ferretti-extended dataset, which in combination with the MM dataset enables separate $C_{12}(t)$ and $C_{13}(t)$ histories to be derived. In conjunction with the corresponding sink histories $\lambda_{12}(t)$ and $\lambda_{13}(t)$ of Eq. (7) that are based on the apparent $\varepsilon$ values from forward modelling (Fig. 3a), inverse modelling yields source histories $S_{12}(t)$ and $S_{13}(t)$ (by solving Eq. (2) for $S_{12}$ and $S_{13}$ in each time step). Their sum recovers the supplied methane source history $S(t)$ and their ratio provides a companion $\delta^{13} \mathrm{C}$ history, $\delta_{S}^{\text {inv }}(t)$.

Figure $3 \mathrm{~b}$ reports $\delta_{S}^{\text {inv }}(t)$ for $\mathrm{S} \& \mathrm{~K}$ and E-H v1.4; that for E-H v1.3 (defined only to 1990) has a similar pattern to E-H v1.4. Note the significantly lighter $\mathrm{S} \& \mathrm{~K}$ source throughout the century except near 1960, which is due to a significantly lower proportion of fossil methane in the S\&K source.

Given that the forward modelled $\delta_{A}(t)$ fits the data quite well over ca. 1910-1988, it is not surprising that inversemodelled $\delta_{S}^{\text {inv }}(t)$ employing the same $\varepsilon$ provides a smoothed match to the corresponding $\delta_{S}(t)$ over the same time interval. The departure of $\delta_{S}^{\text {inv }}(t)$ from $\delta_{S}(t)$ after ca. 1988 is a direct reflection of the poor match between $\delta_{A}(t)$ for E-H v1.4 and the BHD post-anomaly observations, leading to a pronounced swing in $\delta_{S}^{\text {inv }}(t)$ towards a lighter source in the early 1990s. Such a swing would have to be viewed as tentative at least until atmospheric $\delta^{13} \mathrm{C}$ values are better characterized globally, and the inferred variations in sink strength confirmed (Fig. 2b).

\section{The radiomethane budget}

By constructing a source history, $S_{14}(t)$, for each GSIH and combining with the sink history (Eq. 6), the atmospheric history, $C_{14}(t)$, and its associated $\Delta^{14} \mathrm{C}$ history, $\Delta_{A}(t)$, can be deduced. To lowest order $\Delta_{A}(t)$ is independent of $\alpha$. The major challenge is in constructing $S_{14}(t)$, addressed in Sect. 5.1. Section 5.2 compares the construction with available $\Delta^{14} \mathrm{C}$ source data, followed by an examination of $\Delta_{A}(t)$ and its implications in Sect. 5.3.

\subsection{Constructing the radiomethane source}

The generation, emission and atmospheric oxidation of methane is a pathway of the global carbon cycle. Radiomethane is an intrinsic participant in that pathway, and is present in all methane sources whose carbon has been derived from atmospheric $\mathrm{CO}_{2}$ within the last few tens of millennia $\left({ }^{14} \mathrm{C}\right.$ mean life is $\left.8267 \mathrm{yr}\right)$. Fossil methane sources are thus devoid of measurable radiomethane. For both biogenic and pyrogenic sources the radiomethane has cycled through the biosphere and accordingly we refer to it collectively as "biospheric radiomethane" (BR). 


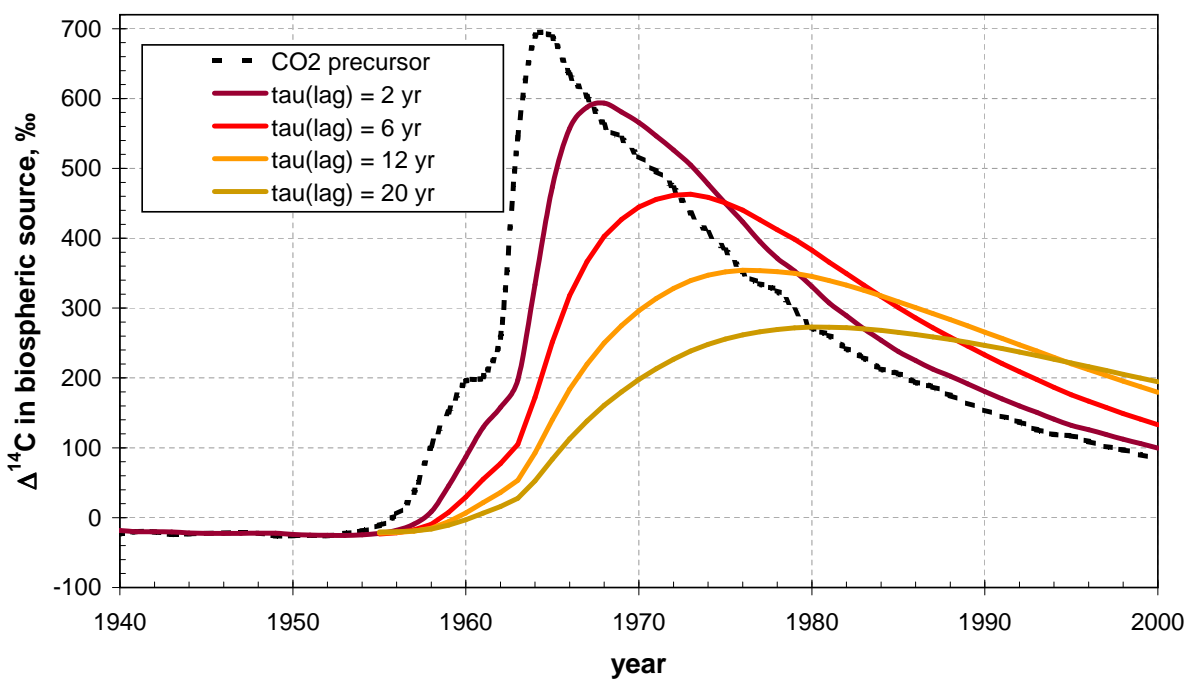

Fig. 4. The simulated history of $\Delta^{14} \mathrm{C}$ in methane from biospheric sources, $\Delta_{B R}(t)$, is shown for the biospheric lag-time distribution of Eq. 8 with several choices for the mean lag time, $\tau_{\text {lag }}$, in the range $2-20$ years. This construction depends only upon the $\Delta^{14} \mathrm{C}$ history in precursor photosynthesised $\mathrm{CO}_{2}, \Delta_{C O 2}(t)$, also shown (Hua and Barbetti, 2004), modulated by the lag-time distribution.

Radiomethane is additionally produced during routine nuclear power generation, and vented to the atmosphere (e.g. Kunz, 1985; Povinec et al., 1986; Veres et al., 1995). We refer to this source as "nuclear power radiomethane" (NPR), and return to it below.

Because $\Delta^{14} \mathrm{C}$ is conserved during biochemical reactions $\mathrm{CO}_{2} \rightarrow$ biosphere and biosphere $\rightarrow \mathrm{CH}_{4}$ by virtue of the fractionation adjustment of Eq. (4b), the $\Delta^{14} \mathrm{C}$ value in a biogenic or pyrogenic methane emission then depends only upon: (a) the $\Delta^{14} \mathrm{C}$ value in atmospheric $\mathrm{CO}_{2}$ at photosynthesis of the included carbon; and (b) the time lapse between the carbon being fixed by photosynthesis and being released as methane. We refer to the time lapse as the "biospheric lag time" and denote it $t_{\text {lag. }}$.

One would expect a wide rage of $t_{\text {lag }}$ values, from less than a year (e.g. cattle consuming fresh grass that is quickly fermented in the rumen, grasslands burned at the end of the growing season) to many decades or longer (e.g. peat methanogenesis, burned forests), so that each methaneproducing ecosystem and management regime would have a characteristic distribution of lag times. With a dearth of data from which to construct a lag-time distribution for any one ecosystem, we postulate a simple distribution for the composite biospheric methane source. Specifically, we apply an exponential distribution of lag times given by:

$F\left(t_{\text {lag }}\right)=\tau_{\text {lag }}^{-1} \exp \left(-t_{\text {lag }} / \tau_{\text {lag }}\right)$

in which $\tau_{\text {lag }}$ is the mean (and standard deviation) lag time in this one-parameter distribution. This need not imply that lag times for any one biogenic or pyrogenic inventory component be distributed according to function (8). The lag-time distribution is discussed further in Sect. 5.2.
Also required for constructing the BR history is a history of $\Delta^{14} \mathrm{C}$ in atmospheric carbon dioxide, denoted $\Delta_{\mathrm{CO} 2}(t)$. Although global coverage of $\Delta_{\mathrm{CO} 2}(t)$ measurements is poor, time series are available in both hemispheres (e.g. Manning et al., 1990; Levin and Kromer, 1997, 2004) and these can be extended using proxy measurements such as of tree rings (Stuiver et al., 1998; Hua and Barbetti, 2004). This enables a globally-representative time series for $\Delta_{\mathrm{CO} 2}(t)$ to be constructed, and we adopt that of Hua and Barbetti (2004), 1955-2000, merged with a pre-1955 series based on the treering record of Stuiver et al. (1998) (Fig. 4). The distinctive "pulse" commencing in ca. 1954 is due to ${ }^{14} \mathrm{C}$ generated through nuclear weapon detonations in the atmosphere prior to the Limited Test Ban Treaty of 1963 (Nydal and Lövseth, 1983). The "bomb ${ }^{14} \mathrm{C}$ " quickly oxidized to ${ }^{14} \mathrm{CO}$, then to ${ }^{14} \mathrm{CO}_{2}$, and thereafter participated in the carbon cycle. Atmospheric ${ }^{14} \mathrm{CO}_{2}$ levels diminished steadily after peaking in 1964-1965 as the radiocarbon transferred to other carbon pools via photosynthesis and ocean dissolution, including indirectly to the atmospheric radiomethane pool.

The ${ }^{14} \mathrm{C}$ history in biospheric methane sources, denoted $\Delta_{B R}(t)$, is a convolution of $\Delta_{\mathrm{CO} 2}(t)$, the lag distribution (8) and radioactive decay. For a particular GSIH the BR source history (expressed in such units as $\left.\mathrm{GBq}\left({ }^{14} \mathrm{CH}_{4}\right) \mathrm{yr}^{-1}\right)$ follows by combining $\Delta_{B R}(t)$ with the strength and $\delta^{13} \mathrm{C}$ of the non-fossil components of the GSIH. To this BR source is added the NPR source whose construction is now described.

NPR is generated principally via the ${ }^{17} \mathrm{O}(\mathrm{n}, \alpha){ }^{14} \mathrm{C}$ reaction on oxygen in the oxide fuel and water coolant, and via ${ }^{14} \mathrm{~N}(\mathrm{n}, \mathrm{p}){ }^{14} \mathrm{C}$ on nitrogen dissolved in the coolant. In the absence of sufficient data on emissions from nuclear facilities to fully characterize the global NPR source strength 
Table 3. Annual electrical power production by pressurized water reactors $(\mathrm{PWRs})^{\mathrm{a}}$.

\begin{tabular}{rrrr}
\hline Year & $\begin{array}{r}\text { Production } \\
\mathrm{GW}_{e} \cdot \mathrm{hr}\end{array}$ & Year & $\begin{array}{r}\text { Production } \\
\mathrm{GW}_{e} \cdot \mathrm{hr}\end{array}$ \\
\hline 1960 & 652 & 1983 & 538260 \\
1961 & 652 & 1984 & 661753 \\
1962 & 1698 & 1985 & 795196 \\
1963 & 1698 & 1986 & 886692 \\
1964 & 2713 & 1987 & 995094 \\
1965 & 2713 & 1988 & 1093808 \\
1966 & 2955 & 1989 & 1179601 \\
1967 & 8053 & 1990 & 1215946 \\
1968 & 9977 & 1991 & 1272698 \\
1969 & 13346 & 1992 & 1329998 \\
1970 & 19002 & 1993 & 1339567 \\
1971 & 30010 & 1994 & 1376117 \\
1972 & 42085 & 1995 & 1408543 \\
1973 & 59420 & 1996 & 1484683 \\
1974 & 98083 & 1997 & 1455015 \\
1975 & 167544 & 1998 & 1513454 \\
1976 & 188409 & 1999 & 1543389 \\
1977 & 251768 & 2000 & 1596707 \\
1978 & 284655 & 2001 & 1655579 \\
1979 & 277913 & 2002 & 1699806 \\
1980 & 328540 & 2003 & 1718317 \\
1981 & 424485 & 2004 & 1752246 \\
1982 & 465855 & 2005 & 1761601 \\
\hline & & & \\
\hline
\end{tabular}

a Dataset kindly supplied by C. Tuniz and J. Mandula, Australian Permanent Mission To UN organizations, Vienna (personal communication, 2002 and 2006), and sourced from IAEA. Production data for 1960-1969 are unavailable, and the entries above for those years are installed capacities multiplied by the average load factor of $44.5 \%$ for $1970-1974$. Data include Soviet-designed PWRs formerly designated WWERs (Water-cooled Water-moderated Energy Reactors).

and evolution, the standard approach has been to argue that PWRs (pressurized water reactors) are the predominant NPR source, and that the source strength is proportional either to the electrical power generated by PWR facilities or to the installed generating capacity as measures of the size of the PWR industry. We express the constant of proportionality in $\mathrm{GBq}\left({ }^{14} \mathrm{CH}_{4}\right)$ per $\mathrm{GW}_{e}$-yr of electricity generated globally by PWRs, and refer to it as the "NPR factor", denoted $\phi$. That PWRs predominate as a source of NPR is due to the use of hydrogen as a cover gas in PWRs that results in most of the ${ }^{14} \mathrm{C}$ being vented as reduced species, ${ }^{14} \mathrm{CH}_{4},{ }^{14} \mathrm{C}_{2} \mathrm{H}_{6}$, etc rather than as ${ }^{14} \mathrm{CO}_{2}$ (Wahlen et al., 1989). Some ${ }^{14} \mathrm{C}$ may be retained in the fuel cladding and released during subsequent fuel reprocessing (Kunz, 1985; Povinec et al., 1986).

Based on measurements at or near individual PWR facilities, local estimates of $\phi$ can be summarized as follows. (i) Detailed measurements at two U.S. reactor sites (Kunz,
1985) yielded values for $\phi$ of 298 and $179 \mathrm{GBq}\left({ }^{14} \mathrm{CH}_{4}\right)$ per $\mathrm{GW}_{e}$-yr generated. These values are based on the total gaseous ${ }^{14} \mathrm{C}$ effluent reported by $\mathrm{Kunz}$, the proportion of ${ }^{14} \mathrm{C}$ as hydrocarbon (90\% and $74 \%$ at the two sites), and the ${ }^{14} \mathrm{CH}_{4}$ content of the hydrocarbon (77\% and $68 \%$ ). (ii) Based on routine monitoring of emissions from a Sovietdesigned four-reactor facility in Hungary, 1988-1993, Veres et al. (1995) estimate hydrocarbon emissions $\left({ }^{14} \mathrm{C}_{n} \mathrm{H}_{m}\right)$ at $740 \mathrm{GBq}$ per $\mathrm{GW}_{e}$-yr generated, which accounted for $94 \%$ of ${ }^{14} \mathrm{C}$ emissions. That emissions are seemingly higher than those from western-designed PWRs may be due to the use of nitrogen solutes as chemical regulators in the primary coolant (Veres et al., 1995). If, based on Kunz (1985), $73 \%$ of the hydrocarbons are ${ }^{14} \mathrm{CH}_{4}, \phi$ would be $540 \mathrm{GBq}\left({ }^{14} \mathrm{CH}_{4}\right)$ per $\mathrm{GW}_{e}$-yr generated. (iii) Based on measurements from a $200 \mathrm{~m}$ tower in The Netherlands combined with trajectories and transport modelling, Eisma et al. (1995) infer ${ }^{14} \mathrm{CH}_{4}$ emission of $260 \pm 50$ ( 1 s.d.) $\mathrm{GBq}$ per year per $\mathrm{GW}_{e}$ installed in NW Europe, which with a European-average load factor of $72 \%$ implies a mean value for $\phi$ of $\left.361 \pm 69 \mathrm{GBq}^{14} \mathrm{CH}_{4}\right)$ per $\mathrm{GW}_{e}$-yr generated.

The 3-fold range in measurement-based estimates for $\phi$ reported above may reflect design, engineering and operational differences among facilities, differing management regimes, different effluent-sampling strategies, uncertain electricity production data and load factors used, the varying proportions of ${ }^{14} \mathrm{CH}_{4}$ in the ${ }^{14} \mathrm{C}$ effluent (which is the usual measurement subject), and the extrapolation to annual emissions and electrical generation. Even the universal proportionality of NPR release to electricity production is poorly founded.

Noting the above uncertainties, we have elected to treat $\phi$ as a time-independent global parameter to be fitted empirically. An annual time series of global PWR-generated electrical energy is compiled from IAEA data (C. Tuniz and J. Mandula, personal communication, 2002 and 2006) (Table 3). While the time series before 1970 is of lower quality, this has minimal practical impact because electrical output from PWRs grew 60-fold between 1970 and 1990.

\subsection{Comparisons with source $\Delta^{14} \mathrm{C}$ measurements}

Simulations of $\Delta_{B R}(t)$ (Fig. 4) are dependent upon the assumed distribution (8) of lag times. An exponential distribution is selected for its simplicity in the absence of guiding data, having just one selectable parameter to which the sensitivity of results can be tested. A disadvantage of such simplicity is that its mean and standard deviation cannot be varied independently (they are numerically equal). Nevertheless, the application of such a continuous distribution should be more realistic than discrete distributions, such as the single lag time of $1 \mathrm{yr}$ for all sources by Manning et al. (1990) and of $45 \mathrm{yr}$ for wetland emissions by Quay et al. (1991), or the 2-component "rapid" and "aged" fractions considered by Wahlen et al. (1989). 
Table 4. Measured $\Delta^{14} \mathrm{C}$ values in methane sources.

\begin{tabular}{|c|c|c|c|}
\hline Year(s) & Location & $\Delta^{14} \mathrm{C}, \%$ & Reference \\
\hline \multicolumn{4}{|c|}{ Wetlands (various) } \\
\hline $1986-88$ & $\mathrm{NY}, \mathrm{USA}\left(43^{\circ} \mathrm{N}\right)$ & $110-197$ & Wahlen et al. (1989) \\
\hline 1987 & $\mathrm{MN}$, Canada $\left(59^{\circ} \mathrm{N}\right)$ & $108-155$ & Wahlen et al. (1989) \\
\hline 1986 & WV, USA $\left(39^{\circ} \mathrm{N}\right)$ & $156-203$ & Wahlen et al. (1989) \\
\hline c. 1987 & AK, USA & $110 \pm 40$ & Quay et al. (1991) \\
\hline c. 1987 & Amazon & $200 \pm 40$ & Quay et al. (1991) \\
\hline c. 1987 & MN, USA & $230 \pm 60$ & Quay et al. (1991) \\
\hline 1988 & AK, USA $\left(61^{\circ} \mathrm{N}\right)$ & $-42-205$ & Martens et al. (1992) \\
\hline 1991 & Thailand $\left(6^{\circ} \mathrm{N}\right)$ & $100 \pm 20$ & Nakagawa et al. (2002) \\
\hline 1991 & MN, USA $\left(47^{\circ} \mathrm{N}\right)$ & $135-161$ & Chanton et al. (1995) \\
\hline 1993-94 & $\mathrm{MN}$, Canada $\left(55^{\circ} \mathrm{N}\right)$ & $148-275$ & Bellisario et al. (1999) \\
\hline \multicolumn{4}{|c|}{ Rice paddies } \\
\hline 1987 & $\mathrm{LA}, \mathrm{USA}\left(30^{\circ} \mathrm{N}\right)$ & $104-181$ & Wahlen et al. (1989) \\
\hline 1990 & Japan $\left(36^{\circ} \mathrm{N}\right)$ & $58-161$ & Tyler et al. (1994a) \\
\hline 1991 & Japan $\left(36^{\circ} \mathrm{N}\right)$ & $127-155$ & Tyler et al. (1994a) \\
\hline 1991 & Thailand $\left(6^{\circ} \mathrm{N}\right)$ & $270 \pm 10$ & Nakagawa et al. (2002) \\
\hline \multicolumn{4}{|c|}{ Ruminants } \\
\hline $1986-88$ & USA & $176-210$ & Wahlen et al. (1989) \\
\hline \multicolumn{4}{|c|}{ Termites } \\
\hline 1987 & USA & $238 \pm 18$ & Wahlen et al. (1989) \\
\hline \multicolumn{4}{|c|}{ Biomass burning } \\
\hline 1987 & USA & $165-403$ & Wahlen et al. (1989) \\
\hline
\end{tabular}

It is instructive to compare $\Delta_{B R}(t)$ simulations with measured $\triangle^{14} \mathrm{C}$ in methane sources. Measurements are available from wetlands, rice paddies, ruminant livestock, termites, and from biomass burning (Table 4). For more detail, see Wahlen et al. (1989) or summaries by Quay et al. (1991) or Nakagawa et al. (2002).

Measurements by Wahlen et al. (1989) cover a variety of sources, all during 1986-1988, and all in North America. During those years $\Delta_{\mathrm{CO} 2}(t)$ declined from $190 \%$ o to $170 \%$ o (global average, Fig. 4), which is supported by measurements of $190 \%$ reported by Wahlen et al. (1989). Consequently, a methane source with $\Delta^{14} \mathrm{C}$ exceeding $\sim 190 \%$ o in 1986 1988 must have been mainly photosynthesised after ca. 1958 (when $\Delta_{\mathrm{CO} 2}(t)$ rose through $190 \%$ ), suggesting mean biospheric lag times of up to $\sim 30$ years, whereas sources with $\Delta^{14} \mathrm{C}$ significantly less than $170 \%$ o must have been largely photosynthesised prior to ca. 1958. Sources characterized by the lag distribution (8) with $\tau_{\mathrm{lag}} \approx 6$ years, a value that best fits data for air extracted from polar ice (Sect. 5.3), would have $\Delta{ }^{14} \mathrm{C} \approx 250-280 \%$ o when measured in 1986-1988 (Fig. 4); for smaller $\tau_{\text {lag }}$ the $\Delta^{14} \mathrm{C}$ values would be lower. Consequently, the Wahlen et al. $\Delta^{14} \mathrm{C}$ measurements for various biogenic sources in the range 100-260\% are generally consistent with $\tau_{\text {lag }} \leq 6$ years and/or $\tau_{\text {lag }}>30$ years.

While the source measurements reported in Table 4 for ca. 1986-1988 are only partially compatible with lag distribution (8) and $\tau_{\mathrm{lag}} \approx 6$ years, those measurements are mainly from northern mid-latitudes (and largely in the Americas) and provide a very sparse coverage of global biogenic and pyrogenic emissions. In the absence of a more detailed coverage we apply distribution (8) as a characterization of the global biospheric source.

\subsection{The atmospheric radiomethane history}

With radiomethane source and sink histories constructed, its atmospheric history can be inferred through forward modelling (Eq. 2), and $\Delta_{A}(t)$ then constructed. The result for E-H v1.4 is shown in Fig. 5a for the $\tau_{\text {lag }}$ values of Fig. 4. Also shown in Fig. 5a are various $\Delta^{14} \mathrm{C}$ measurement records from firn-entrapped air and from the contemporary atmosphere. The latter record includes annually-binned data since 1986, two thirds from the Southern Hemisphere (mainly from BHD) though N-S gradients are not discernible (Quay et al., 1999). (Data are binned in each hemisphere separately, and the hemispheric means then averaged). The earliest contemporary measurements are those of Libby in ca. 1950 (cited by Ehhalt, 1974), and a single measurement by Bainbridge et al. (1961) in air collected in Gary, Indiana in 1960 that may have been contaminated by urban sources of fossil methane.

It should be recognised that air samples extracted from polar firn and ice are associated with a specific depth, and embrace a range of air ages due to diffusion and bubbleenclosure processes (Trudinger et al., 2002). An assigned 

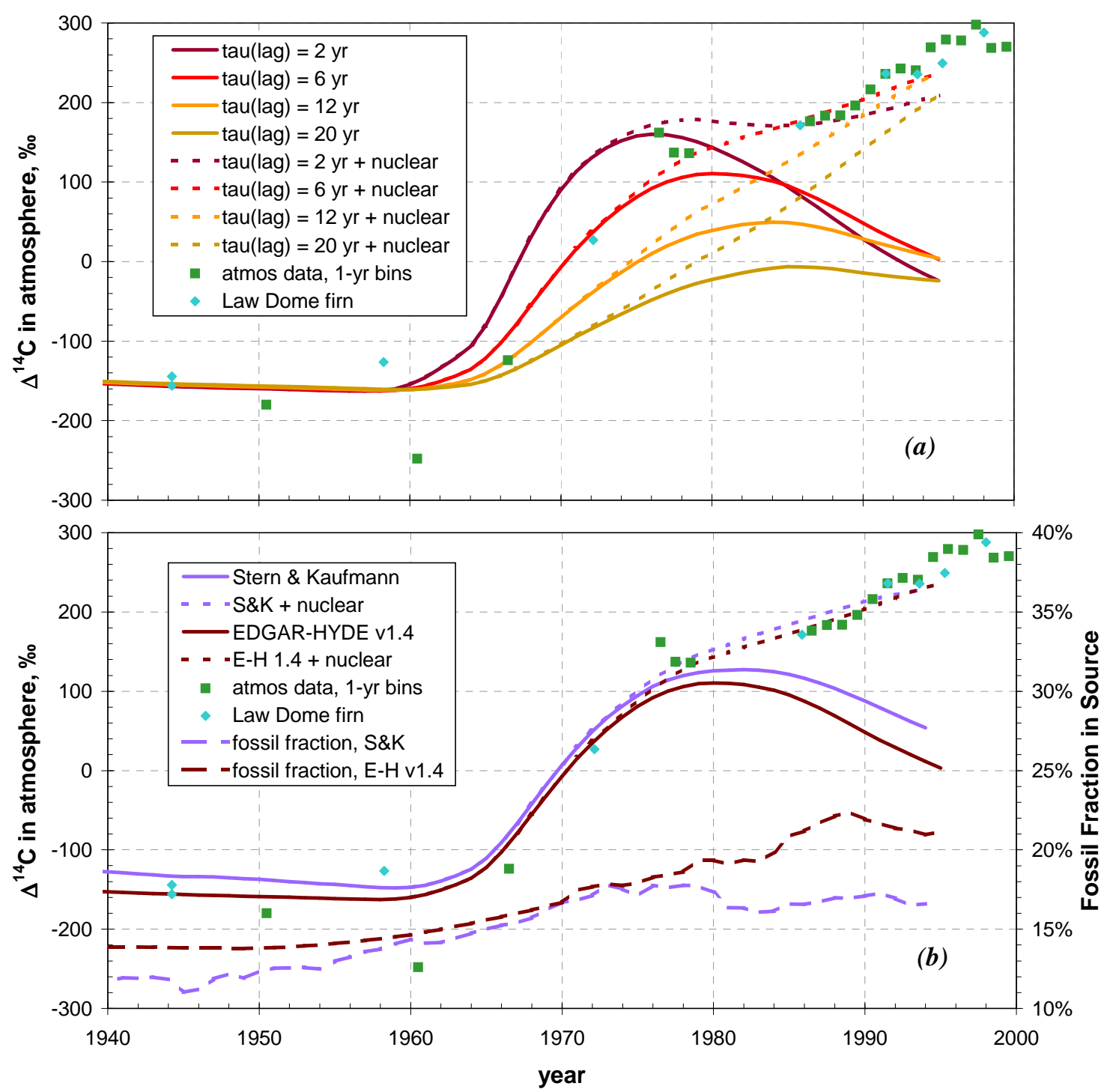

Fig. 5. A simulated $\Delta^{14} \mathrm{C}$ history in atmospheric methane, $\Delta_{A}(t)$. Solid lines show the biospheric radiomethane (BR) only, and the dashed lines show the augmentation from nuclear-power radiomethane (NPR) using a value for the NPR factor, $\phi$, selected to optimise the fit to data for a mean biospheric lag time, $\tau_{\text {lag }}$, of 6 years. Two observational records are reported. The first record is a composite record that includes 230 data points in contemporary air since 1986 from both hemispheres, collated by Lowe et al. (2001) into annual bins that weight each hemisphere equally. That record includes unpublished data kindly contributed by S. Tyler and M. Wahlen, as well as data from New Zealand. Typical measurement uncertainties in the post-1986 binned data are $\pm 7 \%$ ( 1 s.d.) which is about the size of the marker, and these could be magnified 2-3 times to account for the global representativeness of individual samples (based on the spread of individual measurements where these are available in a single bin). The second observational record is based on air trapped in Antarctic firn at Law Dome (Etheridge et al., unpublished data) for which uncertainties due to measurement and due to firn enclosure processes are of order $\pm 10 \%$ ( 1 s.d.). Each firn-air datum additionally carries time uncertainty due to the distribution of air ages in each sample. (a) Simulations for E-H v1.4 for a

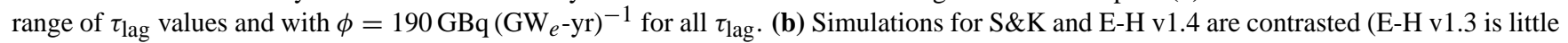
different from v1.4) for $\tau_{\text {lag }}=6$ years, and $\phi=160 \mathrm{GBq}\left(\mathrm{GW}_{e}-\mathrm{yr}\right)^{-1}$ applied to S\&K. Also shown in (b) is the "fossil fraction" in each source construction (long-dash lines, $\mathrm{RH}$ scale), which is the source fraction that is derived from ${ }^{14} \mathrm{C}$-free carbon in geological deposits.

mean air age therefore carries some uncertainty. Detailed analysis of air properties as a function of time should therefore take place after transforming into a function of ice/firn depth for the particular site. Analyses such as these of data in
Fig. 5, to be reported elsewhere (Etheridge et al., manuscript in preparation), suggest a best-fit value $\tau_{\mathrm{lag}}=6 \mathrm{yr}$ (uncertainty $\approx 50 \%$ ). This value is largely determined by data from ca. 1960 to mid 1970s when the rise of the bomb ${ }^{14} \mathrm{C}$ pulse in 
$\Delta_{A}(t)$ was particularly sensitive to $\tau_{\text {lag }}$ (Fig. 5a); the specific datum for ca. 1972 is particularly influential.

The value for $\phi$ used with $\mathrm{E}-\mathrm{H}$ v1.4 in Fig. 5a,

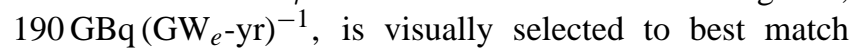
available contemporary atmospheric data for $\tau_{\text {lag }}=6 \mathrm{yr}$. That selection is insensitive to $\tau_{\text {lag }}$ in the range $4-10 \mathrm{yr}$, but for larger $\tau_{\text {lag }}$ a larger $\phi$ would be appropriate. The selected value is also within the range determined through direct measurement at individual nuclear facilities (Sect. 5.1), though near the low end of the range.

With $\tau_{\text {lag }}=6 \mathrm{yr}$ and $\phi=190 \mathrm{GBq}\left(\mathrm{GW}_{e}-\mathrm{yr}\right)^{-1}$, the simulated NPR source comprises $30 \%$ of the total radiomethane source (E-H v1.4 BR + NPR) of 49.4 mole $\mathrm{yr}^{-1}$ $\left(114 \mathrm{TBq}^{-1}\right)$ in 2000.

From the shape of the propagating bomb ${ }^{14} \mathrm{C}$ pulse and the appreciable role of NPR evident in Fig. 5a, it is clear that without NPR emissions atmospheric $\Delta^{14} \mathrm{C}$ would not have been rising at all after the mid-1980s. Indeed, the rate of rise of $\Delta_{A}(t)$ is directly attributable to the rate of growth of NPR emissions, moderated by the rate of decline of the bomb ${ }^{14} \mathrm{C}$ tail, above a baseline that is in proportion to the BR source and thence inversely related to the fossil fraction. This is illustrated in Fig. 5b which contrasts simulations for the E-H and S\&K GSIHs both with $\tau_{\text {lag }}=6 \mathrm{yr}$, and also reports the fossil fractions in those GSIHs. The systematically smaller fossil fraction for S\&K during the 20 years to its 1994 endpoint imposes a higher $\Delta^{14} \mathrm{C}$ baseline than for $\mathrm{E}-\mathrm{H}$, which in turn calls for a weaker NPR source ( $\phi$ smaller by $15 \%$ ) that fails to fully capture the rate of growth in $\Delta_{A}(t)$ during the early 1990s. Thus trading off a smaller BR for a larger NPR leads to a higher rate of growth of $\Delta_{A}(t)$ through the 1990 s, so that a better fit to the observed growth rate requires a GSIH with a larger fossil fraction than E-H in combination with a larger $\phi$.

From Fig. 5 it is clear that determinants of $\Delta_{A}(t)$ fall into four distinct eras: (1) prior to ca. 1960 it is anticorrelated with the fossil fraction, with inter-annual variations smoothed by lag effects; (2) between ca. 1960 and 1975 the rate of rise of the bomb pulse in $\Delta_{A}(t)$ is essentially determined by $\tau_{\text {lag }}$; (3) between ca. 1975 and $1990 \tau_{\text {lag }}$ and the NPR source are both influential; (4) after ca. 1990, and provided that $\tau_{\text {lag }}$ is less than $\sim 15$ years, the NPR source is the dominant determinant of the rate of growth in $\Delta_{A}(t)$ while the fossil fraction influences the absolute level and therefore the fitted $\phi$. It will also be recalled that all ice and firn data have smoothed air ages due to processes of air enclosure (Trudinger et al., 2002). There are several corollaries to these observations.

First, $\Delta{ }^{14} \mathrm{C}$ measurements in the pre-nuclear era can yield estimates for the then-prevailing fossil fraction. Indeed, Ehhalt (1974) made the first fossil fraction estimate at $<20 \%$ based on pre-1960 data. However, for such measurements in the nuclear era, particularly after 1960, reliable fossilfraction estimates are more problematic because of the confounding roles of both the propagating bomb ${ }^{14} \mathrm{C}$ pulse and the poorly quantified NPR source. Several investigators have estimated the fossil fraction from $\Delta{ }^{14} \mathrm{C}$ measurements in the 1980s and 1990s (Lowe et al., 1988; Wahlen et al., 1989; Manning et al., 1990; Quay et al., 1991, 1999), recognising the broad uncertainties that arise from those confounding roles. A key finding of those investigations that is incorporated into IPCC emission inventories (Prather et al., 2001) is that fossil methane sources comprise about $20 \%$ of the contemporary global source (18 $19 \%$ in the early 1990 s, according to Quay et al. (1999), in which the uncertainty is dominated by a $30 \%$ uncertainty assigned to the NPR source strength). We return below to the potential for recalculating the fossil fraction.

A second corollary is that the rate of rise of $\Delta^{14} \mathrm{C}$ during ca. 1960-1975 could provide the best information on the global distribution of biospheric lag times. Previous assumptions about lag times are as diverse as $1 \mathrm{yr}$ postulated by Manning et al. (1990) (in recognition of the possible short lag time associated with wetland emissions) to $45 \mathrm{yr}$ for wetlands by Quay et al. (1991). This work applies a distribution of biospheric lag times with mean of $6 \mathrm{yr}$, although a single datum for ca. 1972 is pivotal to this estimate. More data for 1960-1975 would help elucidate the lag time distribution.

A third corollary is that measurements of $\Delta^{14} \mathrm{C}$ in the post-1990 atmosphere could provide the best estimate of the global-mean NPR factor $\phi$, though this factor is also influenced by both the prevailing fossil fraction and the $\tau_{\text {lag }}$ value if it exceeds $\sim 15$ years. Our simulations to 1995 based on E-H sources favour a $\phi$ of about $190 \mathrm{GBq}$ (82 millimole) ${ }^{14} \mathrm{CH}_{4}$ per $\mathrm{GW}_{e}$-yr of electricity generated by commercial PWRs, an estimate dependent upon the fossil fraction in the E-H GSIH of around 21-23\%. However, none of the GSIHs examined here fully capture the observed early-1990s rate of growth in $\Delta^{14} \mathrm{C}$ (Fig. 5). To further illustrate this, we conducted a simulation test in which the GSIHs based on E-H v1.4 and S\&K were extrapolated smoothly toward stability while maintaining the fossil fraction; Fig. 6 shows the simulations to 2000 , exposing the failure to fully capture the growth in $\Delta^{14} \mathrm{C}$ during the $1990 \mathrm{~s}$. To better capture this growth in the absence of a marked trend in source composition would require a GSIH with a larger fossil component, allowing NPR to take greater prominence.

With the possibility that Soviet-designed PWRs are more prolific NPR emitters than those of Western design (Sect. 5.1), a systematic change in the global mix of PWRs could itself induce a time dependence on $\phi$. However, an analysis of the IAEA data aggregated in Table 3 for the post1986 era of atmospheric measurements reveals no significant trend in the fraction of PWR-generated power from reactors of Soviet design which averages $14.3 \pm 1.4 \%$ (1 s.d.).

The first and third corollaries suggest that ongoing atmospheric time series in $\Delta{ }^{14} \mathrm{C}\left(\mathrm{CH}_{4}\right)$ would enable both the fossil fraction and the NPR factor to be given more certainty through concurrent estimation. This suggestion is addressed in a companion paper (Lassey et al., 2007). 


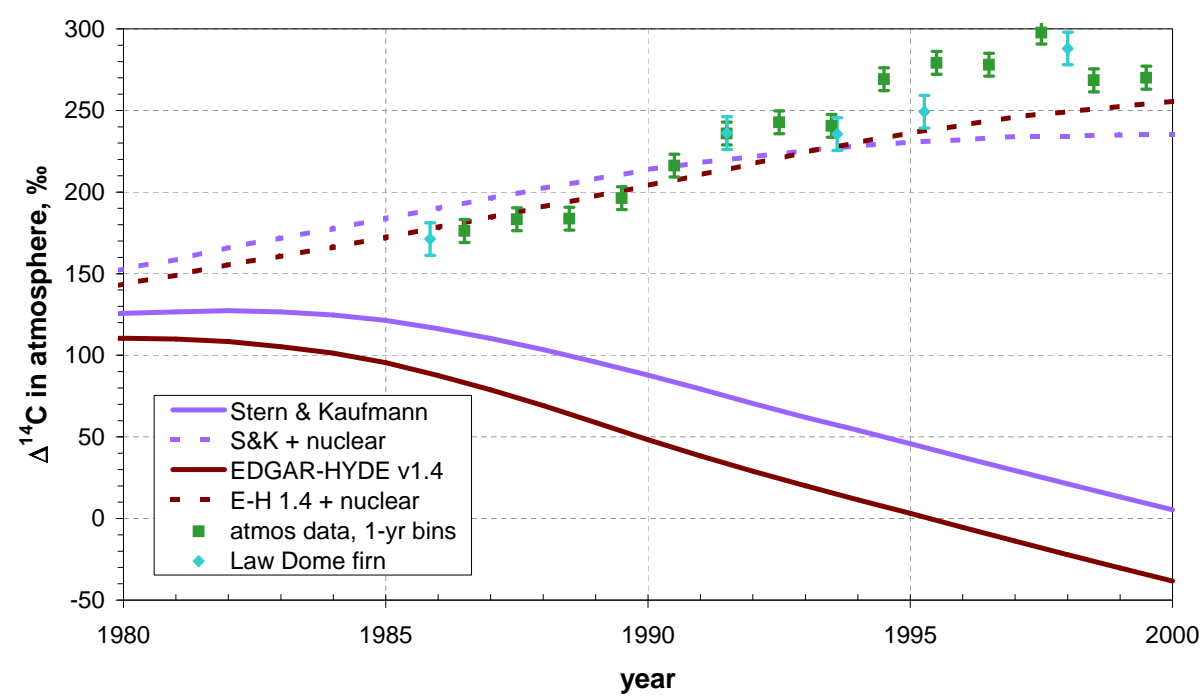

Fig. 6. A magnification of Fig. 5b from 1980 in which simulations of S\&K and E-H v1.4 are extrapolated from 1994 and 1995 respectively through to 2000. The source extrapolations suppose that each source stabilises, nominally in 2004, while holding their 1994 or 1995 proportional compositions. The corresponding sinks are held constant at 1994 or 1995 values. Data uncertainties shown are as described in the caption to Fig. 5: $\pm 7 \%$ for the binned contemporary measurements; $\pm 10 \%$ for the firn measurements, reflecting uncertainties in diffusion and gravitational processes within the firn. The value for $\tau_{\text {lag }}$ is 6 years, and $\phi$ is 160 and $190 \mathrm{GBq}\left(\mathrm{GW}_{\left.e^{-} \mathrm{yr}\right)}{ }^{-1}\right.$ for S\&K and E-H, respectively.

\section{Discussion and conclusions}

This paper presents a comprehensive analysis of the evolution of the methane budget through the 20th century, using model simulations to examine the evolving carbon-isotope composition. The intent is to establish what information about that evolution can be gleaned from isotope measurements made in both contemporary air and air trapped in polar firn and ice, and to what extent bottom-up source inventory constructions are compatible with that evolution. Studies of atmospheric methane from ice-entrapped air are now conveying information on past source inventories through isotope analysis made possible by new developments in mass spectrometry and in polar air extraction (Trudinger et al., 2002; Ferretti et al., 2005; Sowers et al., 2005). However, the airsample size required for ${ }^{14} \mathrm{CH}_{4}$ analyses is still precluding detailed ${ }^{14} \mathrm{CH}_{4}$ information over century time scales.

Global source inventory histories such as the EDGARHYDE (E-H) compilations (Olivier and Berdowski, 2001; van Aardenne et al., 2001; Olivier, 2002) constructed from economic, industrial and agricultural indicators are generally compatible with current knowledge on how the methane budget has evolved. However, the global E-H source, especially E-H v1.4, is weaker than IPCC assessments (Prather et al., 2001), though still within the latter's uncertainty range. By extending that knowledge to include $\delta^{13} \mathrm{C}$ measurements the compatibility of the source mix with atmospheric $\delta^{13} \mathrm{C}$ can be examined, leading to an "apparent" (top-down) isotope fractionation. In the present work we have shown that the global E-H source inventory for the 20th century is indeed generally compatible with newly-emergent $\delta^{13} \mathrm{C}$ data from air trapped in Antarctic ice (Ferretti et al., 2005), with one notable caveat. The apparent fractionation in the global sink, $-6.7 \%$ and $-7.2 \%$ o for v1.3 and v1.4, respectively, is larger in magnitude than commonly accepted for tropospheric $\mathrm{OH}$ in tandem with stratospheric and soil sinks. However, such fractionation is within the range reported by Allan et al. $(2005,2007)$ who invoked active chlorine as an additional highly-fractionating tropospheric sink to account for seasonal amplitudes in mixing ratio and $\delta^{13} \mathrm{C}$ observed for the SW Pacific region. Allan et al. concur with Platt et al. (2004) that the chlorine sink plays a significant role at least in the marine boundary layer. The present analysis lends support to the role of chlorine, which is included in the bottom-up sink construction of Table 2 and without which there would be a discrepancy between the bottom-up and top-down fractionations of $\sim 2 \%$. Although such a discrepancy is not out of range of source $\delta^{13} \mathrm{C}$ uncertainty (Table 1), only a systematic adjustment to the latter throughout the century could preserve the main features of the pattern in $\delta_{A}(t)$.

Alternatively or additionally, a heavier source would require less sink fractionation. This could be achieved with larger fossil and/or pyrogenic components, consistently with arguments that natural gas seeps are appreciably underestimated (e.g. Etiope, 2004) and that carbon emissions from biomass combustion may be under-estimated (e.g. Mouillot et al., 2006). A revision of the fossil methane source would also have to be compatible with estimates based on ${ }^{14} \mathrm{CH}_{4}$ data. Inclusion of the recently-discovered plant 
source (Keppler et al., 2006) in tandem with a reduction in the strength of the wetland and rice sources to avoid double-counting emissions from such ecosystems could both strengthen the global source and make it isotopically heavier.

The more empirically based S\&K source construction (Stern and Kaufmann, 1996), while stronger than the E-H sources, generally provides an inferior fit to 20th century $\delta^{13} \mathrm{C}$ data (Fig. 3a).

Inter-comparing bottom-up and top-down assessments of $\delta^{13} \mathrm{C}$ patterns imposes constraints on the methane budget and its evolution that are the isotopic analogue of constraining the global source using top-down estimation (e.g. Prather et al., 2001). This enables a budget-balancing $\varepsilon$ to be estimated from a century-long pattern (Fig. 3a), an approach that is much more robust than for a budget isolated in time. In effect the $\delta_{A}(t)$ pattern is accompanied by a ribbon of uncertainty of order $\pm 3 \%$ wide, and the optimal apparent KIE, $\varepsilon$, minimises the mismatch between that pattern and the data record (Fig. 3a).

In extending to the ${ }^{14} \mathrm{CH}_{4}$ (radiomethane) cycle, simulations based on the E-H source are broadly compatible with the sparse data available, but are not strongly challenged by those data. This analysis exposes limitations and uncertainties associated with using radiomethane data to constrain the fossil fraction in the methane source after ca. 1960 AD. The difficulty arises because the fossil fraction is only one determinant of atmospheric radiomethane during the nuclear era. Another determinant is biospheric carbon dynamics which control the propagation of the bomb ${ }^{14} \mathrm{C}$ pulse from photosynthesis to methanogenesis (biogenic and pyrogenic). A third determinant is the poorly-quantified nucleogenic production and release of radiomethane from nuclear power facilities. Nevertheless, radiomethane data from the pre-1960 atmosphere could constrain fossil-fraction estimates from contemporaneous anthropogenic activities and from natural geologic sources (Ehhalt, 1974).

While the last two determinants confound fossil-fraction estimation during the nuclear era, they nevertheless provide opportunities. Radiomethane measurements in the atmosphere of 1960-1975 can potentially quantify carbon residence times in the biosphere between photosynthesis and methanogenesis ("biospheric lag times"), while similar measurements for the 1990s could elucidate both the strength of the nuclear-power source ("NPR factor", $\phi$ ) and the fossil fraction. The former suggests a mean biospheric lag time of $6 \mathrm{yr}( \pm \sim 50 \%)$. The latter, addressed in more detail in a companion paper (Lassey et al., 2007), suggests that the E-H sources for the 1990s, augmented by a natural source after Houweling et al. (2000), may understate the fossil methane source: a larger fossil fraction would enable the observed growth in atmospheric ${ }^{14} \mathrm{CH}_{4}$ to be better simulated through a larger role by nuclear-power radiomethane (larger $\phi$ ). With the availability of more and higher-resolution radiomethane measurements in air extracted from polar ice and firn, the roles of these determinants will be further clarified.
What do carbon isotopes tell us about how the methane budget has evolved? Constructions such as E-H of the anthropogenic source history are generally consistent with the reconstructed atmospheric history (from ice-entrapped air), provided that one or both of the following apply: (a) an active chlorine or other highly-fractionating sink is operative to the extent of at least $\sim 10 \mathrm{Tg} \mathrm{yr}^{-1}$ of global methane removal; (b) the global methane source has a proportionately smaller biogenic component (i.e. larger fossil and/or pyrogenic components) than commonly recognised, perhaps partly due to some aerobic plant emissions being mistaken for (anaerobic) biogenic emissions, perhaps partly from under-estimated fossil and/or pyrogenic emissions. Further isotopic data, particularly from ice-entrapped air, could further resolve these ambiguities. Radiomethane measurements are only just beginning to tightly constrain the methane budget, with strong prospects of tighter constraints as more detailed and expansive measurements become available. A companion paper (Lassey et al., 2007) explores constraints currently imposed by atmospheric radiomethane measurements.

Acknowledgements. Discussions with W. Allan and H. Struthers clarified the present understanding of the role of the chlorine sink and of stratospheric processes. We are grateful to C. MacFarling Meure (CSIRO Marine and Atmospheric Research, Australia) for supplying methane mixing ratio data prior to publication, and to S. Tyler (University of California, Irvine, CA, USA) and M. Wahlen (Scripps Institution of Oceanography, La Jolla, CA, USA) for making available unpublished $\Delta^{14} \mathrm{C}$ data for atmospheric methane. Q. Hua (Australian Nuclear Science and Technology Organisation, ANSTO) kindly supplied his dataset of atmospheric ${ }^{14} \mathrm{CO}_{2}$. C. Tuniz and J. Mandula (ANSTO) kindly assembled and supplied data on electricity generation by the nuclear industry while seconded to Australian Permanent Mission to UN organisations and to IAEA in particular. A. Gomez (NIWA, New Zealand) compiled quality-controlled datasets from Baring Head, and provided a smoothed interpolation of atmospheric $\delta^{13} \mathrm{C}$ data. Feedback from E. Nisbet and M. Manning helped improve the manuscript. Staff from the following institutes supported the Antarctic field work, ice archival and gas analyses: the Australian Antarctic Program; the Australian Bureau of Meteorology; CSIRO Marine and Atmospheric Research (Melbourne, Australia), Institute of Arctic and Alpine Research (Boulder, CO, USA). This work was supported by the New Zealand Foundation for Research, Science and Technology under contract C01X0204, and by US National Science Foundation under grant OPP0087357.

Edited by: F. J. Dentener

\section{References}

Allan, W., Lowe, D. C., and Cainey, J. M.: Active chlorine in the remote marine boundary layer: Modeling anomalous measurements of $\delta^{13} \mathrm{C}$ in methane, Geophys. Res. Lett., 28, 3239-3242, $2001 \mathrm{a}$.

Allan, W., Manning, M. R., Lassey, K. R., Lowe, D. C., and Gomez, A. J.: Modeling the variation of $\delta^{13} \mathrm{C}$ in atmospheric methane: 
Phase ellipses and the kinetic isotope effect, Global Biogeochem. Cycles, 15, 467-481, 2001b.

Allan, W., Lowe, D. C., Gomez, A. J., Struthers, H., and Brailsford, G. W.: Interannual variation of ${ }^{13} \mathrm{C}$ in tropospheric methane: Implications for a possible atomic chlorine sink in the marine boundary layer, J. Geophys. Res., 110, D11306, doi:10.1029/2004JD005650, 2005.

Allan, W., Struthers, H., and Lowe, D. C.: Methane carbon isotope effects caused by atomic chlorine in the marine boundary layer: Global model results compared with southern hemisphere measurements, J. Geophys. Res., 112, D04306, doi:10.1029/2006JD007369, 2007.

Andreae, M. O. and Merlet, P.: Emission of trace gases and aerosols from biomass burning, Global Biogeochem. Cycles, 15, 955966, 2001.

Bainbridge, A. E., Suess, H. E., and Friedman, I.: Isotopic composition of atmospheric hydrogen and methane, Nature, 192, 648649, 1961.

Bellisario, L. M., Bubier, J. L., Moore, T. R., and Chanton, J. P.: Controls on $\mathrm{CH}_{4}$ emissions from a northern peatland, Global Biogeochem. Cycles, 13, 81-91, 1999.

Bergamaschi, P., Brühl, C., Brenninkmeijer, C. A. M., Saueressig, G., Crowley, J. N., Grooß, J. U., Fischer, H., and Crutzen, P. J.: Implications of the large carbon kinetic isotope effect in the reaction $\mathrm{CH}_{4}+\mathrm{Cl}$ for the ${ }^{13} \mathrm{C} /{ }^{12} \mathrm{C}$ ratio of stratospheric $\mathrm{CH}_{4}$, Geophys. Res. Lett., 23, 2227-2230, 1996.

Bergamaschi, P., Bräunlich, M., Marik, T., and Brenninkmeijer, C. A. M.: Measurements of the carbon and hydrogen isotopes of atmospheric methane at Izaña, Tenerife: Seasonal cycles and synoptic-scale variations, J. Geophys. Res., 105, 14 531-14 546, 2000.

Bousquet, P., Ciais, P., Miller, J. B., Dlugokencky, E. J., Hauglustaine, D. A., Prigent, C., van der Werf, G. R., Peylin, P., Brunke, E.-G., Carouge, C., Langenfelds, R. L., Lathière, J., Papa, F., Ramonet, M., Schmidt, M., Steele, L. P., Tyler, S. C., and White, J.: Contribution of anthropogenic and natural sources to atmospheric methane variability, Nature, 443, 439-443, 2006.

Brenninkmeijer, C. A. M., Lowe, D. C., Manning, M. R., Sparks, R. J., and van Velthoven, P. F. J.: The ${ }^{13} \mathrm{C},{ }^{14} \mathrm{C}$, and ${ }^{18} \mathrm{O}$ isotopic composition of $\mathrm{CO}, \mathrm{CH}_{4}$, and $\mathrm{CO}_{2}$ in the higher southern latitudes lower stratosphere, J. Geophys. Res., 100, 26 163-26172, 1995.

Cantrell, C. A., Shetter, R. E., McDaniel, A. H., Calvert, J. G., Davidson, J. A., Lowe, D. C., Tyler, S. C., Cicerone, R. J., and Greenberg, J. P.: Carbon kinetic isotope effect in the oxidation of methane by the hydroxyl radical, J. Geophys. Res., 95, $22455-$ 22 462, 1990.

Chanton, J. P., Rutkowski, C. M., Schwartz, C. C., Ward, D. E., and Boring, L.: Factors influencing the stable carbon isotopic signature of methane from combustion and biomass burning, J. Geophys. Res., 105, 1867-1877, 2000.

Chanton, J. P., Bauer, J. E., Glaser, P. A., Siegel, D. I., Kelley, C. A., Tyler, S. C., Romanowicz, E. H., and Lazrus, A.: Radiocarbon evidence for the substrates supporting methane formation within northern Minnesota peatlands, Geochim. Cosmochim. Acta, 59, 3663-3668, 1995.

Conny, J. M. and Currie, L. A.: The isotopic characterization of methane, non-methane hydrocarbons and formaldehyde in the troposphere, Atmos. Environ., 30, 621-638, 1996.
Craig, H.: The geochemistry of stable carbon isotopes, Geochim. Cosmochim. Acta, 3, 53-92, 1953.

Craig, H.: Isotopic standards for carbon and oxygen and correction factors for mass spectrometric analysis of carbon dioxide, Geochim. Cosmochim. Acta, 12, 133-149, 1957.

Craig, H., Chou, C. C., Welhan, J. A., Stevens, C. M., and Engelkemeir, A.: The isotopic composition of methane in polar ice cores, Science, 242, 1535-1539, 1988.

Crowley, J. N., Saueressig, G., Bergamaschi, P., Fischer, H., and Harris, G. W.: Carbon kinetic isotope effect in the reaction $\mathrm{CH}_{4}+\mathrm{Cl}$ : a relative rate study using FTIR spectroscopy, Chem. Phys. Lett., 303, 268-274, 1999.

Cunnold, D. M., Steele, L. P., Fraser, P. J., Simmonds, P. G., Prinn, R. G., Weiss, R. F., Porter, L. W., O’Doherty, S., Langenfelds, R. L., Krummel, P. B., Wang, H. J., Emmons, L., Tie, X. X., and Dlugokencky, E. J.: In situ measurements of atmospheric methane at GAGE/AGAGE sites during 19852000 and resulting source inferences, J. Geophys. Res., 107, doi:10.1029/2001JD001226, 2002.

Dentener, F., Peters, W., Krol, M., van Weele, M., Bergamaschi, P., and Lelieveld, J.: Interannual variability and trend of $\mathrm{CH}_{4}$ lifetime as a measure for $\mathrm{OH}$ changes in the 1979-1993 time period, J. Geophys. Res., 108, 4442, doi:10.1029/2002JD002916, 2003.

Dlugokencky, E. J., Masarie, K. A., Lang, P. M., and Tans, P. P.: Continuing decline in the growth rate of the atmospheric methane burden, Nature, 393, 447-450, 1998.

Dlugokencky, E. J., Myers, R. C., Lang, P. M., Masarie, K. A., Crotwell, A. M., Thoning, K. W., Hall, B. D., Elkins, J. W., and Steele, L. P.: Conversion of NOAA atmospheric dry air $\mathrm{CH}_{4}$ mole fractions to a gravimetrically prepared standard scale, J. Geophys. Res., 110, D18306, doi:10.1029/2005JD006035, 2005.

Ehhalt, D. H.: The atmospheric cycle of methane, Tellus, 26, 58-70, 1974.

Eisma, R., Vermeulen, A. T., and van der Borg, K.: ${ }^{14} \mathrm{CH}_{4}$ emissions from nuclear power plants in northwestern Europe, Radiocarbon, 37, 475-483, 1995.

Etheridge, D. M., Steele, L. P., Francey, R. J., and Langenfelds, R. L.: Atmospheric methane between 1000 A.D. and present: Evidence of anthropogenic emissions and climate variability, J. Geophys. Res., 103, 15 979-15 993, 1998.

Etheridge, D. M., Smith, A. M., Lowe, D. C., Trudinger, C. M., Langenfelds, R. L., Steele, L. P., Lassey, K. R., Levchenko, V. A., and Manning, M. R.: Sources of atmospheric methane during the 20th century from methane isotopic measurements in Antarctic firn air, in: $8^{\text {th }}$ Scientific Assembly of IAMAS, Innsbruck, Austria, pp. 106, 2001.

Etiope, G.: New directions: GEM - Geologic emissions of methane, the missing source in the atmospheric methane budget, Atmos. Environ., 38, 3099-3100, 2004.

Etiope, G. and Klusman, R. W.: Geologic emissions of methane to the atmosphere, Chemosphere, 49, 777-789, 2002.

Ferretti, D. F., Miller, J. B., White, J. W. C., Etheridge, D. M., Lassey, K. R., Lowe, D. C., MacFarling Meure, C. M., Dreier, M. F., Trudinger, C. M., van Ommen, T. D., and Langenfelds, R. L.: Unexpected changes to the global methane budget over the past 2000 years, Science, 309, 1714-1717, 2005.

Ferretti, D. F., Miller, J. B., White, J. W. C., Lassey, K. R., Lowe, D. C., and Etheridge, D. M.: Stable isotopes provide revised global limits of aerobic methane emissions from plants, Atmos. Chem. 
Phys., 7, 237-241, 2007,

http://www.atmos-chem-phys.net/7/237/2007/.

Fiore, A. M., Horowitz, L. W., Dlugokencky, E. J., and West, J. J.: Impact of meteorology and emissions on methane trends, 1990-2004, Geophys. Res. Lett., 33, L12809, doi:10.1029/2006GL026199, 2006.

Francey, R. J., Manning, M. R., Allison, C. E., Coram, S. A., Etheridge, D. M., Langenfelds, R. L., Lowe, D. C., and Steele, L. P.: A history of $\delta^{13} \mathrm{C}$ in atmospheric $\mathrm{CH}_{4}$ from the Cape Grim Air Archive and Antarctic firn air, J. Geophys. Res., 104, 23 631$23643,1999$.

Fung, I., John, J., Lerner, J., Matthews, E., Prather, M., Steele, L. P., and Fraser, P. J.: Three-dimensional model synthesis of the global methane cycle, J. Geophys. Res., 96, 13 033-13065, 1991.

Hein, R., Crutzen, P. J., and Heimann, M.: An inverse modeling approach to investigate the global atmospheric methane cycle, Global Biogeochem. Cycles, 11, 43-76, 1997.

Houweling, S., Dentener, F., and Lelieveld, J.: Simulation of preindustrial methane to constrain the global source strength of natural wetlands, J. Geophys. Res., 105, 17 243-17 255, 2000.

Houweling, S., Kaminski, T., Dentener, F., Lelieveld, J., and Heimann, M.: Inverse modeling of methane sources and sinks using the adjoint of a global transport model, J. Geophys. Res., 104, 26 137-26 160, 1999.

Houweling, S., Röckmann, T., Aben, I., Keppler, F., Krol, M., Meirink, J. F., Dlugokencky, E. J., and Frankenberg, C.: Atmospheric constraints on global emissions of methane from plants, Geophys. Res. Lett., 33, L15821, doi:10.1029/2006GL026162, 2006.

Hua, Q. and Barbetti, M.: Review of tropospheric bomb ${ }^{14} \mathrm{C}$ data for carbon cycle modeling and age calibration studies, Radiocarbon, 46, 1273-1298, 2004.

Kammen, D. M. and Marino, B. D.: On the origin and magnitude of pre-industrial anthropogenic $\mathrm{CO}_{2}$ and $\mathrm{CH}_{4}$ emissions, Chemosphere, 26, 69-86, 1993.

Karlsdóttir, S. and Isaksen, I. S. A.: Changing methane lifetime: Possible cause for reduced growth, Geophys. Res. Lett., 27, 9396, 2000.

Kasischke, E. S. and Penner, J. E.: Improving global estimates of atmospheric emissions from biomass burning, J. Geophys. Res., 109, D14S01, doi:10.1029/2004JD004972, 2004.

Keppler, F., Hamilton, J. T. G., Braß, M., and Röckmann, T.: Methane emissions from terrestrial plants under aerobic conditions, Nature, 439, 187-191, 2006.

Kirchgessner, D. A., Piccot, S. D., and Masemore, S. S.: An improved inventory of methane emissions from coal mining in the United States, J. Air Waste Manage. Assoc., 50, 1904-1919, 2000.

Kirschbaum, M. U. F., Bruhn, D., Etheridge, D. M., Evans, J. R., Farquhar, G. D., Gifford, R. M., Paul, K. I., and Winters, A. J.: A comment on the quantitative significance of aerobic methane release by plants, Funct. Plant Biol., 33, 521-530, 2006.

Kunz, C.: Carbon-14 discharge at three light-water reactors, Health Phys., 49, 25-35, 1985.

Lacroix, A. V.: Unaccounted-for sources of fossil and isotopicallyenriched methane and their contribution to the emissions inventory: A review and synthesis, Chemosphere, 26, 505-557, 1993.

Lassey, K. R., Lowe, D. C., and Manning, M. R.: The trend in atmo- spheric methane $\delta^{13} \mathrm{C}$ and implications for isotopic constraints on the global methane budget, Global Biogeochem. Cycles, 14, 41-49, 2000.

Lassey, K. R., Scheehle, E. A., and Kruger, D.: Towards reconciling national emission inventories for methane with the global budget, Environ. Sci., 2, 193-204, 2005.

Lassey, K. R., Lowe, D. C., and Smith, A. M.: The atmospheric cycling of radiomethane and the "fossil fraction" of the methane source, Atmos. Chem. Phys., 7, 2141-2149, 2007, http://www.atmos-chem-phys.net/7/2141/2007/.

Lelieveld, J., Crutzen, P. J., and Dentener, F. J.: Changing concentration, lifetime and climate forcing of atmospheric methane, Tellus, 50B, 128-150, 1998.

Lelieveld, J., Peters, W., Dentener, F. J., and Krol, M. C.: Stability of tropospheric hydroxyl chemistry, J. Geophys. Res., 107, 4715, doi:10.1029/2002JD002272, 2002.

Levin, I. and Kromer, B.: Twenty years of high precision atmospheric ${ }^{14} \mathrm{CO}_{2}$ observations at Schauinsland station, Germany, Radiocarbon, 39, 205-218, 1997.

Levin, I. and Kromer, B.: The tropospheric ${ }^{14} \mathrm{CO}_{2}$ level in midlatitudes of the Northern Hemisphere (1959-2003), Radiocarbon, 46, 1261-1272, 2004

Lowe, D., Manning, M., Levin, I., Wahlen, M., Tyler, S., Etheridge, D., and Lassey, K.: Radiocarbon content of atmospheric methane and the 'fossil fraction' of emissions, in: 8th Scientific Assembly of IAMAS, Innsbruck, Austria, pp. 106, 2001.

Lowe, D. C., Brenninkmeijer, C. A. M., Tyler, S. C., and Dlugokencky, E. J.: Determination of the isotopic composition of atmospheric methane and its application in the Antarctic, J. Geophys. Res., 96, 15 445-15 467, 1991.

Lowe, D. C., Manning, M. R., Brailsford, G. W., and Bromley, A. M.: The 1991-1992 atmospheric methane anomaly: Southern Hemisphere ${ }^{13} \mathrm{C}$ decrease and growth rate fluctuations, Geophys. Res. Lett., 24, 857-860, 1997.

Lowe, D. C., Brenninkmeijer, C. A. M., Manning, M. R., Sparks, R. J., and Wallace, G.: Radiocarbon determination of atmospheric methane at Baring Head, New Zealand, Nature, 332, 522-525, 1988.

Lowe, D. C., Koshy, K., Bromley, T., Allan, W., Struthers, H., Mani, F., and Maata, M.: Seasonal cycles of mixing ratio and ${ }^{13} \mathrm{C}$ in atmospheric methane at Suva, Fiji, J. Geophys. Res., 109, D23308, doi:10.1029/2004JD005166, 2004.

Lowe, D. C., Allan, W., Manning, M. R., Bromley, A., Brailsford, G., Ferretti, D., Gomez, A., Knobben, R., Martin, R., Mei, Z., Moss, R., Koshy, K., and Maata, M.: Shipboard determinations of the distribution of ${ }^{13} \mathrm{C}$ in atmospheric methane in the Pacific, J. Geophys. Res., 104, 26 125-26 135, 1999.

MacFarling Meure, C., Etheridge, D., Trudinger, C., Steele, P., Langenfelds, R., van Ommen, T., Smith, A., and Elkins, J.: Law Dome $\mathrm{CO}_{2}, \mathrm{CH}_{4}$ and $\mathrm{N}_{2} \mathrm{O}$ ice core records extended to 2000 years BP, Geophys. Res. Lett., 33, L14810, doi:10.1029/2006GL026152, 2006.

Mak, J. E., Manning, M. R., and Lowe, D. C.: Aircraft observations of $\delta^{13} \mathrm{C}$ of atmospheric methane over the Pacific in August 1991 and 1993: Evidence of an enrichment in ${ }^{13} \mathrm{CH}_{4}$ in the Southern Hemisphere, J. Geophys. Res., 105, 1329-1335, 2000.

Manning, M. R., Lowe, D. C., Moss, R. C., Bodeker, G. E., and Allan, W.: Short term variations in the oxidizing power of the atmosphere, Nature, 436, 1001-1004, 2005. 
Manning, M. R., Lowe, D. C., Melhuish, W. H., Sparks, R. J., Wallace, G., Brenninkmeijer, C. A. M., and McGill, R. C.: The use of radiocarbon measurements in atmospheric studies, Radiocarbon, 32, 37-58, 1990.

Martens, C. S., Kelley, C. A., Chanton, J. P., and Showers, W. J.: Carbon and hydrogen isotopic characterization of methane from wetlands and lakes of the Yukon-Kuskokwim Delta, Western Alaska, J. Geophys. Res., 97, 16 689-16 701, 1992.

McCarthy, M. C., Connell, P., and Boering, K. A.: Isotopic fractionation of methane in the stratosphere and its effect on free tropospheric isotopic compositions, Geophys. Res. Lett., 28, 36573660, 2001

Mikaloff Fletcher, S. E., Tans, P. P., Bruhwiler, L. M., Miller, J. B., and Heimann, M.: $\mathrm{CH}_{4}$ sources estimated from atmospheric observations of $\mathrm{CH}_{4}$ and its ${ }^{13} \mathrm{C} /{ }^{12} \mathrm{C}$ isotopic ratios: 2. Inverse modeling of $\mathrm{CH}_{4}$ fluxes from geographical regions, Global Biogeochem. Cycles, 18, GB4005, doi:10.1029/2004GB002224, 2004.

Miller, J. B., Mack, K. A., Dissly, R., White, J. W. C., Dlugokencky, E. J., and Tans, P. P.: Development of analytical methods and measurements of ${ }^{13} \mathrm{C} /{ }^{12} \mathrm{C}$ in atmospheric $\mathrm{CH}_{4}$ from NOAA Climate Monitoring and Diagnostics Laboratory Global Air Sampling Network, J. Geophys. Res., 107, doi:10.1029/2001JD000630, 2002.

Mook, W. G. and van der Plicht, J.: Reporting ${ }^{14} \mathrm{C}$ activities and concentrations, Radiocarbon, 41, 227-239, 1999.

Mouillot, F., Narasimha, A., Balkanski, Y., Lamarque, J.-F., and Field, C. B.: Global carbon emissions from biomass burning in the 20th century, Geophys. Res. Lett., 33, L01801, doi:10.1029/2005GL024707, 2006.

Nakagawa, F., Yoshida, N., Sugimoto, A., Wada, E., Yoshioka, T., Ueda, S., and Vijarnsorn, P.: Stable isotope and radiocarbon compositions of methane emitted from tropical rice paddies and swamps in Southern Thailand, Biogeochem., 61, 1-19, 2002.

Nydal, R. and Lövseth, K.: Tracing bomb ${ }^{14} \mathrm{C}$ in the atmosphere 1962-1980, J. Geophys. Res., 88, 3621-3642, 1983.

Olivier, J. G. J.: On the quality of global emission inventories, PhD thesis, Utrecht University, Utrecht, Netherlands, 167 pp, 2002.

Olivier, J. G. J. and Berdowski, J. J. M.: Global emission sources and sinks, in: The Climate System, edited by: Berdowski, J., Guicherit, R., and Heij, B. J., A. A. Balkema Publishers/Swets \& Zeitlinger Publishers, Lisse, The Netherlands, 33-78, 2001.

Parsons, A. J., Newton, P. C. D., Clark, H., and Kelliher, F. M.: Scaling methane emissions from vegetation, TREE, 21, 423424, 2006.

Platt, U., Allan, W., and Lowe, D.: Hemispheric average $\mathrm{Cl}$ atom concentration from ${ }^{13} \mathrm{C} /{ }^{12} \mathrm{C}$ ratios in atmospheric methane, Atmos. Chem. Phys., 4, 2393-2399, 2004,

http://www.atmos-chem-phys.net/4/2393/2004/.

Povinec, P., Chudý, M., and Sivo, A.: Anthropogenic radiocarbon: past, present, and future, Radiocarbon, 28, 668-672, 1986

Prather, M., Ehhalt, D., Dentener, F., Derwent, R., Dlugokencky, E., Holland, E., Isaksen, I., Katima, J., Kirchhoff, V., Matson, P., Midgley, P., and Wang, M.: Atmospheric chemistry and greenhouse gases, in: Climate Change 2001: The Scientific Basis, Contribution of Working Group I to the Third Assessment Report of the Intergovernmental Panel on Climate Change, edited by: Houghton, J. T., Ding, Y., Griggs, D. J., Nogeur, M., van der Linden, P. J., Dai, X., Maskell, K., and Johnson, C. A., Cam- bridge University Press, Cambridge, UK, 239-287, 2001.

Prinn, R. G., Huang, J., Weiss, R. F., Cunnold, D. M., Fraser, P. J., Simmonds, P. G., McCulloch, A., Harth, C., Reimann, S., Salameh, P., O’Doherty, S., Wang, R. H. J., Porter, L. W., Miller, B. R., and Krummel, P. B.: Evidence for variability of atmospheric hydroxyl radicals over the past quarter century, Geophys. Res. Lett., 32, L07809, doi:10.1029/2004GL022228, 2005.

Quay, P. D., Stutsman, J., Wilbur, D., Snover, A., Dlugokencky, E. J., and Brown, T.: The isotopic composition of atmospheric methane, Global Biogeochem. Cycles, 13, 445-461, 1999.

Quay, P. D., King, S. L., Stutsman, J., Wilbur, D. O., Steele, L. P., Fung, I., Gammon, R. H., Brown, T. A., Farwell, G. W., Grootes, P. M., and Schmidt, F. H.: Carbon isotopic composition of atmospheric $\mathrm{CH}_{4}$ : fossil and biomass burning source strengths, Global Biogeochem. Cycles, 5, 25-47, 1991.

Robbins, R. C., Cavanagh, L. A., Salas, L. J., and Robinson, E.: Analysis of ancient atmospheres, J. Geophys. Res., 78, 53415344, 1973.

Rosenlof, K. H. and Holton, J. R.: Estimates of stratospheric residual circulation using the downward control principle, J. Geophys. Res., 98, 10 465-10 479, 1993.

Ruddiman, W. F. and Thomson, J. S.: The case for human causes of increased atmospheric $\mathrm{CH}_{4}$ over the last 5000 years, Quaternary Science Reviews, 20, 1769-1777, 2001.

Saueressig, G., Bergamaschi, P., Crowley, J. N., Fischer, H., and Harris, G. W.: Carbon kinetic isotope effect in the reaction of $\mathrm{CH}_{4}$ with $\mathrm{Cl}$ atoms, Geophys. Res. Lett., 22, 1225-1228, 1995.

Saueressig, G., Crowley, J. N., Bergamaschi, P., Brühl, C., Brenninkmeijer, C. A. M., and Fischer, H.: Carbon 13 and D kinetic isotope effects in the reaction of $\mathrm{CH}_{4}$ with $\mathrm{O}\left({ }^{1} \mathrm{D}\right)$ and $\mathrm{OH}$ : New laboratory measurements and their implications for the isotopic composition of stratospheric methane, J. Geophys. Res., 106, 23 127-23 138, 2001

Schimel, D., Alves, D., Enting, I. G., Heimann, M., Joos, F., Raynaud, D., Wigley, T. M. L., Prather, M., Derwent, R., Ehhalt, D., Fraser, P., Sanhueza, E., Zhou, X., Jonas, P., Charlson, R., Rodhe, H., Sadasivan, S., Shine, K., Fouquart, Y., Ramaswamy, V., Solomon, S., Srinivasan, J., Albritton, D., Derwent, R., Isaksen, I., Lal, M., and Wuebbles, D.: Radiative forcing of climate change. In: Climate Change 1995: The Science of Climate Change, edited by: Houghton, J. T., Meira Filho, L. G., Callander, B. A., Harris, N., Kattenberg, A., and Maskell, K., Cambridge University Press, Cambridge, UK, 65-131, 1996.

Snover, A. K. and Quay, P. D.: Hydrogen and carbon kinetic effects during soil uptake of atmospheric methane, Global Biogeochem. Cycles, 14, 25-39, 2000.

Sowers, T., Bernard, S., Aballain, O., Chappellaz, J., Barnola, J.M., and Marik, T.: Records of the ${ }^{13} \mathrm{C}$ of atmospheric $\mathrm{CH}_{4}$ over the last 2 centuries as recorded in Antarctic snow and ice, Global Biogeochem. Cycles, 19, GB2002, doi:10.1029/2004GB002408, 2005.

Stern, D. I. and Kaufmann, R. K.: Estimates of global anthropogenic methane emissions 1860-1993, Chemosphere, 33, 159176, 1996

Struthers, H., Allan, W., Lowe, D. C., and Bhaskaran, B.: A comparison of the transport of long lived atmospheric trace gas species from two advection schemes incorporated into an atmospheric general circulation model, Tellus, accepted, 2007.

Stuiver, M.: Workshop on ${ }^{14} \mathrm{C}$ data reporting, Radiocarbon, 22, 
964-966, 1980.

Stuiver, M. and Polach, H. A.: Reporting of ${ }^{14} \mathrm{C}$ data, Radiocarbon, 19, 355-363, 1977.

Stuiver, M., Reimer, P. J., and Braziunas, T. F.: High-precision radiocarbon age calibration for terrestrial and marine samples, Radiocarbon, 40, 1127-1151, 1998.

Subak, S.: Methane from the house of Tudor and the Ming Dynasty: Anthropogenic emissions in the sixteenth century, Chemosphere, 29, 843-854, 1994.

Sugawara, S., Nakazawa, T., Shirakawa, Y., Kawamura, K., and Aoki, S.: Vertical profile of the carbon isotope ratio of stratospheric methane over Japan, Geophys. Res. Lett., 24, 29892992, 1997.

Tans, P. P.: A note on isotope ratios and the global atmospheric methane budget, Global Biogeochem. Cycles, 11, 77-81, 1997.

Trudinger, C. M., Etheridge, D. M., Rayner, P. J., Enting, I. G., Sturrock, G. A., and Langenfelds, R. L.: Reconstructing atmospheric histories from measurements of air composition in firn, J. Geophys. Res., 107, 4780, doi:10.1029/2002JD002545, 2002.

Tyler, S. C., Crill, P. M., and Brailsford, G. W.: ${ }^{13} \mathrm{C} /{ }^{12} \mathrm{C}$ fractionation of methane during oxidation in a temperate forested soil, Geochim. Cosmochim. Acta, 58, 1625-1633, 1994a.

Tyler, S. C., Brailsford, G. W., Yagi, K., Minami, K., and Cicerone, R. J.: Seasonal variations in methane flux and $\delta^{13} \mathrm{CH}_{4}$ values for rice paddies in Japan and their implications, Global Biogeochem. Cycles, 8, 1-12, 1994b.

Tyler, S. C., Ajie, H. O., Rice, A. L., Cicerone, R. J., and Tuazon, E. C.: Experimentally determined kinetic isotope effects in the reaction of $\mathrm{CH}_{4}$ with $\mathrm{Cl}$ : Implications for atmospheric $\mathrm{CH}_{4}$, Geophys. Res. Lett., 27, 1715-1718, 2000.

van Aardenne, J. A., Dentener, F. J., Olivier, J. G. J., Klein Goldewijk, C. G. M., and Lelieveld, J.: A $1^{\circ} \times 1^{\circ}$ resolution data set of historical anthropogenic trace gas emissions for the period 1890 1990, Global Biogeochem. Cycles, 15, 909-928, 2001.
Veres, M., Hertelendi, E., Uchrin, G., Csaba, E., Barnabás, I., Ormai, P., Volent, G., and Futó, I.: Concentration of radiocarbon and its chemical forms in gaseous effluents, environmental air, nuclear waste and primary water of a pressurized water reactor power plant in Hungary, Radiocarbon, 37, 497-504, 1995.

Wahlen, M., Tanaka, N., Henry, R., Deck, B., Zeglen, J., Vogel, J. S., Southon, J., Shemesh, A., Fairbanks, R., and Broecker, W.: Carbon-14 in methane sources and in atmospheric methane: The contribution from fossil carbon, Science, 245, 286-290, 1989.

Wang, J. S., McElroy, M. B., Spivakovsky, C. M., and Jones, D. B. A.: On the contribution of anthropogenic $\mathrm{Cl}$ to the increase in $\delta^{13} \mathrm{C}$ of atmospheric methane, Global Biogeochem. Cycles, 16, 1047, doi:10.1029/2001GB001572, 2002.

Wang, J. S., Logan, J. A., McElroy, M. B., Duncan, B. N., Megretskaia, I. A., and Yantosca, R. M.: A 3-D model analysis of the slowdown and interannual variability in the methane growth rate from 1988 to 1997, Global Biogeochem. Cycles, 18, GB3011, doi:10.1029/2003GB002180, 2004.

Wang, Y. and Jacob, D. J.: Anthropogenic forcing on tropospheric ozone and $\mathrm{OH}$ since preindustrial times, J. Geophys. Res., 103, 31 123-31 135, 1998.

Warwick, N. J., Bekki, S., Law, K. S., Nisbet, E. G., and Pyle, J. A.: The impact of meteorology on the interannual growth rate of atmospheric methane, Geophys. Res. Lett., 29, 1947, doi:10.1029/2002GL015282, 2002.

Waugh, D. W. and Hall, T. M.: Age of stratospheric air: theory, observations, and models, Rev. Geophys., 40, 1010, doi:10.1029/2000RG000101, 2002. 